\title{
Antibacterial Profile in vitro and in vivo of New 1,4-Naphthoquinones Tethered to 1,2,3-1H-Triazoles Against the Planktonic Growth of Streptococcus mutans
}

\author{
Mônica P. Gomes, ${ }^{\circledR a, b, c}$ Eduardo M. Correia, ${ }^{๑ a}$ Max W. L. Gomes, ${ }^{\circledR a, c}$ Claudio C. C. dos Santos, ${ }^{\oplus a, c}$ \\ Caroline S. Barros, ${ }^{\circledR d}$ Fernanda V. de Abreu, ${ }^{\circledR b}$ Leonardo S. Antunes, ${ }^{\circledR b}$ Vitor F. Ferreira, ${ }^{\circledR e}$ \\ Mariana C. Gonçalves, ${ }^{\odot f}$ Gabriel O. de Resende, ${ }^{\oplus g}$ Daniel T. G. Gonzaga, ${ }^{\oplus h}$ Carla E. C. Pinto, ${ }^{\oplus d}$ \\ Izabel C. N. P. Paixão ${ }^{\circledR *, a, c}$ and Fernando C. da Silva ${ }^{\circledR} *, f$ \\ ${ }^{a}$ Laboratório de Virologia Molecular e Biotecnologia Marinha, Universidade Federal Fluminense, \\ 24210-201 Niterói-RJ, Brazil \\ ${ }^{b}$ Instituto de Odontologia, Universidade Federal Fluminense, 24210-140 Niterói-RJ, Brazil \\ cPrograma de Pós-Graduação em Ciências e Biotecnologia, Universidade Federal Fluminense, \\ 24210-141 Niterói-RJ, Brazil \\ ${ }^{d}$ Departamento de Imunobiologia, Instituto de Biologia, Universidade Federal Fluminense, \\ 24210-201 Niterói-RJ, Brazil \\ ${ }^{e}$ Departamento de Tecnologia Farmacêutica, Faculdade de Farmácia, Universidade Federal Fluminense, \\ 24241-000 Niterói-RJ, Brazil

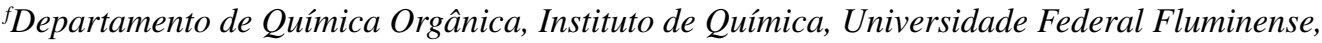 \\ 24210-141 Niterói-RJ, Brazil \\ ${ }^{8}$ Instituto Federal de Educação, Ciência e Tecnologia do Rio de Janeiro, Unidade Maracanã, \\ 20270-021 Rio de Janeiro-RJ, Brazil \\ ${ }^{h}$ Unidade de Farmácia, Fundação Centro Universitário Estadual da Zona Oeste, \\ 23070-200 Rio de Janeiro-RJ, Brazil
}

\begin{abstract}
The cariogenic processes are mainly caused by the bacterium Streptococcus mutans (S. mutans) and consist of the demineralization of the tooth that occurs when the acid production overcomes the natural repair or if a problem occurs in the last one. In this work, we performed the synthesis of twenty-one 1,4-naphthoquinones tethered to 1,2,3-1H-triazoles (8a-8k and $\mathbf{9 a - 9 j})$, antibacterial evaluation against the $S$. mutans in vitro and the acute toxicity of the better ones in vivo. We observed strong inhibition results in the disc diffusion test ranging, the halos of inhibitions, from $18.66( \pm 0.57)$ to $29( \pm 2.64) \mathrm{mm}$, and good values in the minimum inhibitory concentration ( 5 to $50 \mu \mathrm{g}$ ), for the compounds $9 \mathbf{e}, \mathbf{9 h}, \mathbf{9 i}$ and $\mathbf{9 j}$. Furthermore, they do not have a cytotoxic effect at the concentrations tested. Besides that, in the in vivo test, they show some slight alteration in the histopathological analyses and the biochemistry. Thus, we found four potential candidates to become instruments for the treatment of cavities.
\end{abstract}

Keywords: quinones, heterocycles, azoles, dental cavities, oral treatments

\section{Introduction}

The search for information on the activity of natural and synthetic substances against infections caused by microorganisms has been conducted over the last few

*e-mail: izabeluff@gmail.com; fcsilva@id.uff.br

Editor handled this article: Brenno A. D. Neto (Associate) years due to health, social, environmental and economic needs. The cariogenic processes are mainly caused by the bacterium Streptococcus mutans (S. mutans) and consist of the demineralization of the tooth that occurs when the acid production overcomes the natural repair or if some problem occurs in the last one. ${ }^{1}$ The fermentation of sugar into acids decreases the $\mathrm{pH}$ near the teeth surface, creating an optimal environment for $S$. mutans to grow, also reducing 
the competition with other microorganisms that cannot survive under low $\mathrm{pH}$ conditions on the surface of the teeth. ${ }^{2}$ This bacteria causes tooth decay and attaches to teeth in two ways: when it has sucrose in the surface, forming dental plaque and the other not dependent of sucrose, using a surface protein named antigen I/II. ${ }^{3,4}$

This process affects 60 to $90 \%$ of the children and a number of adults in industrialized countries. ${ }^{5}$ However, results have shown that the cases of dental caries in Brazil decreased significantly from 1980 until 2003, probably due to the fluoridated water. ${ }^{6}$ Despite the reduction previously observed, ${ }^{6}$ a recent study ${ }^{7}$ demonstrated an increase in global oral conditions, mainly for caries disease, between 1990 and 2010. This demonstrates the importance of controlling oral microbiology, mainly the Streptococcus mutans population, to reduce the propensity of cariogenic dental plaque development. ${ }^{8}$ Moreover, the number of resistant bacteria to the conventional medicines used in clinics has been growing, including the Streptococcus viridans group, which includes $S$. mutans, showing the need to seek a way to inhibit these bacteria and circumvent this problem. ${ }^{9-12}$

Although naphthoquinones ${ }^{13}$ and 1,2,3-triazoles ${ }^{14}$ are, separately, of great importance due to their diverse biological applications, substances that contain these two nuclei together have been studied in recent years against various diseases and have shown that it is a molecular combination with potential synergism, that is, they are more bioactive when coupled than when isolated. ${ }^{15}$ Thus, considering that naphthoquinones can inhibit the bacteria ${ }^{16,17}$ by interacting with enzymes topoisomerases I and II, impairing the deoxyribonucleic acid (DNA) replication ${ }^{18}$ and triazole derivatives, demonstrated strong antibacterial properties, ${ }^{19,20}$ herein we describe the synthesis of twentyone 1,4-naphthoquinones tethered to 1,2,3-1H-triazoles, antibacterial evaluation against the $S$. mutans in vitro and the acute toxicity of the better ones in vivo.

\section{Experimental}

\section{Chemistry}

\section{Materials and methods}

The solvents and reagents were obtained from Merck Brazil (São Paulo, Brazil) and used without further purification. For qualitative monitoring of the reaction progress, analytical thin-layer chromatography (TLC) was produced with silica gel plates (Merck, TLC silica gel 60 F254, São Paulo, Brazil), and the plots were visualized using UV light (Sigma-Aldrich, São Paulo, Brazil). For purification of the final compounds, column chromatography was performed with silica gel 60 (Merck
70-230 mesh, São Paulo, Brazil). Melting points, when necessary, were obtained on a Thermo Scientific 9100 apparatus (Waltham, USA) and were uncorrected. All final products were submitted to complete spectroscopic characterization. Infrared spectra were measured with $\mathrm{KBr}$ pellets on a PerkinElmer (São Paulo, Brazil) model 1420 Fourier transform infrared (FTIR) spectrophotometer, and the spectra were calibrated using the $1601.8 \mathrm{~cm}^{-1}$ polystyrene absorbances. Nuclear magnetic resonance (NMR) spectra were obtained with a Varian Unity Plus VXR $500 \mathrm{MHz}$ (Palo Alto, USA) instrument in dimethyl sulfoxide (DMSO- $d_{6}$, Sigma-Aldrich, São Paulo, Brazil) solutions. The chemical shift data were reported in units of $\delta$ (ppm) downfield from tetramethylsilane (TMS) or the solvent, either of which was used as an internal standard, coupling constants $(J)$ are reported in hertz and refer to apparent peak multiplicities. High-resolution mass spectra (HRMS) were recorded on a MICROMASS Q-TOF mass spectrometer (Waters, Milford, USA).

\section{General procedure for $\mathbf{6}$ and $\mathbf{7}$}

In an Erlenmeyer flask containing of amine-quinone $(12.1 \mathrm{mmol}, \mathbf{4} \text { or } 5)^{21}$ was added an aqueous solution of $\mathrm{HCl}$ $50 \%$ sufficient to cover the solid, keeping the mixture in an ice bath with $\mathrm{NaCl}\left(0-5^{\circ} \mathrm{C}\right)$. Then, a solution of sodium nitrite $(18.1 \mathrm{mmol})$ in $30 \mathrm{~mL}$ of distilled water was added slowly under vigorous stirring and kept for more $30 \mathrm{~min}$ $\left(0-5^{\circ} \mathrm{C}\right)$. Next, sodium azide $(48.7 \mathrm{mmol})$ dissolved in $60 \mathrm{~mL}$ of water was slowly added and kept for more $1 \mathrm{~h}$ $\left(0-5^{\circ} \mathrm{C}\right)$. Finally, the mixture was filtered and washed with water. The product was used in the subsequent step without previous purification.

\section{General procedure for $\mathbf{8 a - 8 k}$ and $\mathbf{9 a - 9 j}$}

In a $250 \mathrm{~mL}$ round bottom flask containing a solution of azide-quinone $(0.5 \mathrm{mmol})$ in DMSO $(40 \mathrm{~mL})$ and water $(20 \mathrm{~mL})$ were added copper sulfate $(0.15 \mathrm{mmol})$, sodium ascorbate $(0.2 \mathrm{mmol})$ and corresponding alkyne $(0.6 \mathrm{mmol})$. The mixture was kept under constant stirring for $24 \mathrm{~h}$ at room temperature. Then, the mixture was extracted with ethyl acetate $(3 \times 50 \mathrm{~mL})$, washed with distilled water $(3 \times 50 \mathrm{~mL})$ and the organic layer was dried with anhydrous sodium sulfate, filtered and concentrated under low pressure. The crude product was chromatographed in column using a gradient of hexane/ethyl acetate as eluent.

2-Chloro-3-((4-(4-(hydroxymethyl)-1H-1,2,3-triazol-1-yl) phenyl)amino)naphthalene-1,4-dione (8a)

Orange solid, yield 53\%, mp 240-242 ${ }^{\circ} \mathrm{C}$; IR (KBr) $v / \mathrm{cm}^{-1}$ 3210, 1671, 1640, 1596, 1570, 1521, 1497, 1441, 1410, 1331, 1287, 1260, 1235, 1189, 1165, 1137, 1111, 
$1063,1046,1033,1009,991,912,852,833,810,787,762$ $736,714,683,649,635,609,541,528 ;{ }^{1} \mathrm{H}$ NMR $(500 \mathrm{MHz}$, DMSO- $\left.d_{6}\right) \delta 4.63(1 \mathrm{H}, \mathrm{s}), 7.24(2 \mathrm{H}, \mathrm{d}, J 8.7 \mathrm{~Hz}), 7.75-7.79$ $(3 \mathrm{H}, \mathrm{m}), 7.84(1 \mathrm{H}, \mathrm{t}, J 7.5 \mathrm{~Hz}), 8.00(1 \mathrm{H}, \mathrm{d}, J 7.5 \mathrm{~Hz})$, $8.04(1 \mathrm{H}, \mathrm{dd}, J 1.1$ and $7.5 \mathrm{~Hz}), 8.55(1 \mathrm{H}, \mathrm{s}) ;{ }^{13} \mathrm{C} \mathrm{NMR}$ $\left(125 \mathrm{MHz}, \mathrm{DMSO}-d_{6}\right) \delta 55.5,70.2,103.5,115.7,120.2$, $121.2,124.5,126.4,126.0,131.0,132.9,133.3,135.0$, 144.3, 149.5, 176.3, 180.6; HRMS (ESI) $\mathrm{m} / \mathrm{z}$, calcd. for $\mathrm{C}_{19} \mathrm{H}_{13} \mathrm{ClN}_{4} \mathrm{O}_{3} \mathrm{Na}^{+}[\mathrm{M}+\mathrm{Na}]^{+}:$403.0574, found: 403.0584 .

2-Chloro-3-((4-(4-(2-hydroxyethyl)-1H-1,2,3-triazol-1-yl) phenyl)amino)naphthalene-1,4-dione (8b)

Orange solid, yield $58 \%$, mp $234-236{ }^{\circ} \mathrm{C}$; IR $(\mathrm{KBr})$ $v / \mathrm{cm}^{-1}$ 3292, 3137, 3096, 2918, 2875, 2324, 1731, 1667, 1597, 1575, 1521, 1492, 1448, 1412, 1379, 1352, 1331, 1287, 1260, 1217, 1195, 1135, 1112, 1053, 1016, 990, $912,849,838,803,790,735,717,682,670,629,615,581$, 542,$529 ;{ }^{1} \mathrm{H}$ NMR $\left(500 \mathrm{MHz}, \mathrm{DMSO}-d_{6}\right) \delta 2.92(2 \mathrm{H}, \mathrm{t}$, $J 6.8 \mathrm{~Hz}), 3.77(2 \mathrm{H}, \mathrm{q}, J 6.8 \mathrm{~Hz}), 7.31(2 \mathrm{H}, \mathrm{d}, J 8.7 \mathrm{~Hz}), 7.79$ $(2 \mathrm{H}, \mathrm{d}, J 8.7 \mathrm{~Hz}), 7.81-1.90(2 \mathrm{H}, \mathrm{m}), 8.04-8.07(2 \mathrm{H}, \mathrm{m})$, $8.44(1 \mathrm{H}, \mathrm{s}), 9.25(1 \mathrm{H}, \mathrm{s}) ;{ }^{13} \mathrm{C}$ NMR $\left(75 \mathrm{MHz}\right.$, DMSO- $\left.d_{6}\right)$ $\delta$ 29.7, 60.8, 116.5, 121.0, 120.1, 125.0, 126.6, 127.0, 130.9, 132.4, 133.5, 133.7, 135.2, 139.6, 143.5, 146.1, 177.2, 180.4; HRMS (ESI) $m / z$, calcd. for $\mathrm{C}_{20} \mathrm{H}_{15} \mathrm{ClN}_{4} \mathrm{O}_{3} \mathrm{Na}^{+}$ $[\mathrm{M}+\mathrm{Na}]^{+}:$417.0731, found: 417.0724 .

2-((4-(4-Butyl-1H-1,2,3-triazol-1-yl)phenyl)amino)-3-chloronaphthalene-1,4-dione (8c)

Brown solid, yield 93\%, mp $192-194{ }^{\circ} \mathrm{C}$; IR (KBr) $v / \mathrm{cm}^{-1} 3326,2929,2857,1670,1647,1594,1572,1521$, 1498, 1410, 1331, 1287, 1259, 1237, 1190, 1136, 1109, 1043, 1018, 989, 912, 850, 834, 808, 787, 734, 716, 682, 616,$542 ;{ }^{1} \mathrm{H}$ NMR $\left(500 \mathrm{MHz}, \mathrm{DMSO}-d_{6}\right) \delta 0.94(3 \mathrm{H}$, t, $J 7.4 \mathrm{~Hz}), 1.40(2 \mathrm{H}$, sex, $J 7.4 \mathrm{~Hz}), 1.68(2 \mathrm{H}$, quin, $J 7.4 \mathrm{~Hz}), 2.72(2 \mathrm{H}, \mathrm{t} J 7.4 \mathrm{~Hz}), 7.31(2 \mathrm{H}, \mathrm{d}, J 8.7 \mathrm{~Hz}), 7.79$ $(2 \mathrm{H}, \mathrm{d}, J 8.7 \mathrm{~Hz}), 7.83-7.90(2 \mathrm{H}, \mathrm{m}), 8.04-8.07(2 \mathrm{H}, \mathrm{m})$, $8.46(1 \mathrm{H}, \mathrm{s}), 9.27(1 \mathrm{H}, \mathrm{s}) ;{ }^{13} \mathrm{C}$ NMR $\left(75 \mathrm{MHz}, \mathrm{DMSO}-d_{6}\right)$ $\delta$ 14.0, 22.1, 25.1, 31.4, 116.5, 120.1, 120.4, 125.0, 126.6, 127.0, 130.9, 132.4, 133.5, 133.7, 135.2, 139.5, 143.5, 148.5, 177.2, 180.4; HRMS (ESI) $\mathrm{m} / \mathrm{z}$, calcd. for $\mathrm{C}_{22} \mathrm{H}_{19} \mathrm{ClN}_{4} \mathrm{O}_{2} \mathrm{Na}^{+}[\mathrm{M}+\mathrm{Na}]^{+}: 429.1095$, found: 429.1088 .

2-Chloro-3-((4-(4-(1-hydroxyethyl)-1H-1,2,3-triazol-1-yl) phenyl)amino)naphthalene-1,4-dione (8d)

Red solid, yield 68\%, mp $225-227^{\circ} \mathrm{C}$; IR (KBr) $v / \mathrm{cm}^{-1}$ $3218,1673,1639,1595,1568,1521,1504,1436,1412$, 1332, 1289, 1256, 1240, 1192, 1169, 1140, 1105, 1046, 1020, 1003, 990, 914, 890, 852, 839, 805, 738, 717, 682, 613, 547; ${ }^{1} \mathrm{H}$ NMR (500 MHz, DMSO- $\left.d_{6}\right) \delta 1.50(2 \mathrm{H}, \mathrm{d}$, $J 6.5 \mathrm{~Hz}), 4.93(1 \mathrm{H}, \mathrm{q}, J 6.5 \mathrm{~Hz}), 7.31(2 \mathrm{H}, \mathrm{d}, J 8.7 \mathrm{~Hz})$, 7.84-7.90 (2H, m), 8.05-8.07 (2H, m), $8.52(1 \mathrm{H}, \mathrm{s}), 9.28$
$(1 \mathrm{H}, \mathrm{s}) ;{ }^{13} \mathrm{C}$ NMR $\left(126 \mathrm{MHz}, \mathrm{DMSO}-d_{6}\right) \delta 23.6,61.5$, $115.8,119.4,119.5,124.4,126.1,126.5,130.3,131.8$, 132.7, 133.2, 134.7, 139.0, 142.9, 153.6, 176.7, 179.9; HRMS (ESI) $\mathrm{m} / z$, calcd. for $\mathrm{C}_{22} \mathrm{H}_{19} \mathrm{ClN}_{4} \mathrm{O}_{2} \mathrm{Na}^{+}[\mathrm{M}+\mathrm{Na}]^{+}$: 417.0731, found: 417.0708 .

2-Chloro-3-((4-(4-(2-hydroxybutan-2-yl)-1H-1,2,3-triazol1-yl)phenyl)amino)naphthalene-1,4-dione (8e)

Red solid, yield $58 \%$, mp $204-206{ }^{\circ} \mathrm{C}$; IR (KBr) $v / \mathrm{cm}^{-1}$ $3269,3123,2962,1676,1635,1594,1562,1524,1501,1447$, $1412,1369,1334,1287,1261,1241,1190,1162,1137,1110$, 1050, 1019, 989, 914, 851, 837, 806, 789, 737, 719, 682, $634,619,547$; ' ${ }^{1} \mathrm{H}$ NMR $\left(500 \mathrm{MHz}, \mathrm{DMSO}-d_{6}\right) \delta 0.83(3 \mathrm{H}$, t, $J 7.5 \mathrm{~Hz}), 1.52(3 \mathrm{H}, \mathrm{s}), 1.82-1.86(2 \mathrm{H}, \mathrm{m}), 7.31(3 \mathrm{H}, \mathrm{d}$, $J 8.7 \mathrm{~Hz}), 7.81-7.83(3 \mathrm{H}, \mathrm{m}), 7.86(1 \mathrm{H}, \mathrm{td}, J 1.5$ and $7.5 \mathrm{~Hz})$, 8.05-8.07 $(2 \mathrm{H}, \mathrm{m}), 8.45(1 \mathrm{H}, \mathrm{s}), 9.27(1 \mathrm{H}, \mathrm{s}) ;{ }^{13} \mathrm{C} \mathrm{NMR}$ (75 MHz, DMSO- $\left.d_{6}\right) \delta 8.7,28.5,35.8,70.2,116.5,119.7$, 120.1, 125.0, 126.6, 127.0, 130.9, 132.5, 133.5, 133.7, 135.2, 139.6, 143.6, 156.4, 177.2, 180.4; HRMS (ESI) $\mathrm{m} / z$, calcd. for $\mathrm{C}_{22} \mathrm{H}_{19} \mathrm{ClN}_{4} \mathrm{O}_{3} \mathrm{Na}^{+}[\mathrm{M}+\mathrm{Na}]^{+}: 445.1044$, found: 445.1053 .

2-Chloro-3-((4-(4-(2-hydroxypropan-2-yl)-1H-1,2,3-triazol1-yl)phenyl)amino)naphthalene-1,4-dione (8f)

Red solid, yield 56\%, mp 194-196 ${ }^{\circ} \mathrm{C}$; IR (KBr) $v / \mathrm{cm}^{-1}$ 3216, 2977, 2108, 1674, 1639, 1595, 1569, 1519, 1498, 1436, $1415,1332,1287,1238,1176,1139,1110,1043,1018,992$, $959,914,852,835,810,790,737,717,683,636,608,544$; ${ }^{1} \mathrm{H}$ NMR $\left(500 \mathrm{MHz}, \mathrm{DMSO}-d_{6}\right) \delta 1.56(6 \mathrm{H}, \mathrm{s}), 5.02(1 \mathrm{H}, \mathrm{s})$, $7.31(2 \mathrm{H}, \mathrm{d}, J 8.7 \mathrm{~Hz}), 7.80-7.84(3 \mathrm{H}, \mathrm{m}), 7.88(1 \mathrm{H}, \mathrm{td}, J 1.3$ and 7.5 Hz), 8.05-8.07 $(2 \mathrm{H}, \mathrm{m}), 8.48(1 \mathrm{H}, \mathrm{s}), 9.28(1 \mathrm{H}, \mathrm{s})$; ${ }^{13} \mathrm{C}$ NMR (75 MHz, DMSO- $d_{6}$ ) $\delta 31.1,67.5,116.6,119.1$, 120.2, 125.0, 126.0, 126.6, 127.0, 130.9, 132.4, 133.7, 135.2, 139.6, 143.6, 157.3, 177.2, 180.4; HRMS (ESI) $\mathrm{m} / z$, calcd. for $\mathrm{C}_{21} \mathrm{H}_{17} \mathrm{ClN}_{4} \mathrm{O}_{3} \mathrm{Na}^{+}[\mathrm{M}+\mathrm{Na}]^{+}$: 431.0887, found: 431.0881 .

2-Chloro-3-((4-(4-phenyl-1H-1,2,3-triazol-1-yl)phenyl) amino)naphthalene-1,4-dione $\mathbf{( 8 g}$ )

Red solid, yield $30 \%$, mp $266-268^{\circ} \mathrm{C}$; IR (KBr) $v / \mathrm{cm}^{-1}$ 3327, 3138, 2920, 1664, 1642, 1600, 1573, 1525, 1505, 1482, 1456, 1436, 1407, 1332, 1288, 1259, 1233, 1184, 1134, 1109, 1073, 1040, 1018, 992, 950, 911, 849, 833, $821,806,785,766,714,693,680,631,614,531 ;{ }^{1} \mathrm{H}$ NMR $\left(500 \mathrm{MHz}\right.$, DMSO- $\left.d_{6}\right) \delta 7.36(2 \mathrm{H}, \mathrm{d}, J 8.7 \mathrm{~Hz}), 7.38-7.40$ $(1 \mathrm{H}, \mathrm{m}), 7.50(2 \mathrm{H}, \mathrm{t}, J 7.5 \mathrm{~Hz}), 7.84(1 \mathrm{H}, \mathrm{td}, J 1.1$ and 7.5 Hz), 7.88-7.90 (3H, m), 7.94-7.95 (2H, m), 8.06-8.07 $(2 \mathrm{H}, \mathrm{m}), 9.17(1 \mathrm{H}, \mathrm{s}), 9.31(1 \mathrm{H}, \mathrm{s}) ;{ }^{13} \mathrm{C}$ NMR $(125 \mathrm{MHz}$, DMSO- $\left.d_{6}\right) \delta 116.8,119.9,120.4,121.6,124.9,125.9$, 126.6, 127.0, 128.6, 129.4, 130.9, 130.9, 132.4, 133.2, 133.8, 135.2, 140.0, 143.5, 147.8, 177.2, 180.4; HRMS (ESI) $\mathrm{m} / z$, calcd. for $\mathrm{C}_{24} \mathrm{H}_{14} \mathrm{ClN}_{4} \mathrm{O}_{2}[\mathrm{M}-\mathrm{H}]^{-}: 425.0806$, found: 425.0801 . 
2-Chloro-3-((3-(4-(3-chloropropyl)-1H-1,2,3-triazol-1-yl) phenyl)amino)naphthalene-1,4-dione (8h)

Brown solid, yield $45 \%$, mp 183-185 ${ }^{\circ} \mathrm{C}$; IR (KBr) $v / \mathrm{cm}^{-1}$ 3331, 2922, 2852, 1667, 1644, 1599, 1572, 1525, 1504, 1459, 1442, 1408, 1332, 1286, 1260, 1236, 1188, 1135, 1108, 1046, 1017, 990, 911, 851, 832, 806, 789, 732, 717, $682,654,625 ;{ }^{1} \mathrm{H}$ NMR (500 MHz, DMSO- $\left.d_{6}\right) \delta 2.15(2 \mathrm{H}$, m), $2.87(2 \mathrm{H}, \mathrm{t}, J 7.4 \mathrm{~Hz}), 3.74(\mathrm{t}, J 6.6 \mathrm{~Hz}), 7.32(2 \mathrm{H}, \mathrm{d}$, $J 8.7 \mathrm{~Hz}), 7.79-7.84(3 \mathrm{H}, \mathrm{m}), 7.88(1 \mathrm{H}, \mathrm{td}, J 1.3$ and $7.5 \mathrm{~Hz})$, 8.05-8.07 (2H, m), $8.52(1 \mathrm{H}, \mathrm{s}), 9.29(1 \mathrm{H}, \mathrm{s}) ;{ }^{13} \mathrm{C} \mathrm{NMR}$ $\left(75 \mathrm{MHz}, \mathrm{DMSO}-d_{6}\right) \delta 22.9,32.1,45.1,116.6,120.2,120.8$, 125.0, 126.6, 127.0, 130.9, 132.4, 133.4, 133.7, 135.2, 139.7, 143.5, 147.1, 177.2, 180.5; HRMS (ESI) $\mathrm{m} / \mathrm{z}$, calcd. for $\mathrm{C}_{21} \mathrm{H}_{17} \mathrm{Cl}_{2} \mathrm{~N}_{4} \mathrm{O}_{2}[\mathrm{M}+\mathrm{H}]^{+}:$427.0728, found: 427.0718 .

2-Chloro-3-((4-(4-(((tetrahydro-2H-pyran-2-yl)oxy)methyl)$1 H$-1,2,3-triazol-1-yl)phenyl)amino)naphthalene-1,4-dione (8i)

Orange solid, yield $70 \%$, mp $181-183{ }^{\circ} \mathrm{C}$; IR (KBr) $v / \mathrm{cm}^{-1}$ 3264, 2937, 1670, 1598, 1576, 1522, 1498, 1442, 1411, 1333, 1287, 1259, 1235, 1200, 1189, 1134, 1111, 1034, 941, 901, 869, 849, 839, 809, 791, 735, 717, 682, 616,$532 ;{ }^{1} \mathrm{H}$ NMR $\left(500 \mathrm{MHz}, \mathrm{DMSO}-d_{6}\right) \delta 1.48-1.57(4 \mathrm{H}$, $\mathrm{m}), 1.63-1.79(2 \mathrm{H}, \mathrm{m}), 3.49-3.53(1 \mathrm{H}, \mathrm{m}), 3.82-3.87(1 \mathrm{H}$, m), $4.63(1 \mathrm{H}, \mathrm{d}, J 12.3 \mathrm{~Hz}), 4.76-4.80(2 \mathrm{H}, \mathrm{m}), 7.32(2 \mathrm{H}, \mathrm{d}$, $J 8.9 \mathrm{~Hz}), 7.81-7.84(3 \mathrm{H}, \mathrm{m}), 7.88(1 \mathrm{H}, \mathrm{td}, J 1.3$ and $7.5 \mathrm{~Hz})$, 8.05-8.06 (1H, m), 8.06-8.07 (1H, m), 8.70 (1H, s), 9.29 $(1 \mathrm{H}, \mathrm{s}) ;{ }^{13} \mathrm{C}$ NMR $\left(75 \mathrm{MHz}, \mathrm{DMSO}-d_{6}\right) \delta 19.4,25.5,30.6$, 60.0, 61.9, 97.8, 116.7, 120.4, 122.4, 124.9, 126.6, 127.0, $130.9,132.4,133.3,133.7,135.2,139.9,143.5,145.6$, 177.2, 180.4; HRMS (ESI) $m / z$, calcd. for $\mathrm{C}_{24} \mathrm{H}_{22} \mathrm{ClN}_{4} \mathrm{O}_{4}$ : $[\mathrm{M}+\mathrm{H}]^{+}:$465.1329, found: 465.1322 .

(1-(4-((3-Chloro-1,4-dioxo-1,4-dihydronaphthalen-2-yl) amino)phenyl)-1 $\mathrm{H}$-1,2,3-triazol-4-yl)methyl acetate (8j)

Orange solid, yield $60 \%$, mp $208-210{ }^{\circ} \mathrm{C}$; IR (KBr) $v / \mathrm{cm}^{-1}$ 3230, 3137, 2922, 2852, 1730, 1676, 1648, 1597, $1575,1523,1505,1459,1445,1412,1377,1332,1289$, 1256, 1244, 1228, 1189, 1138, 1111, 1040, 1018, 991, 960, $914,850,837,808,789,771,735,718,702,682,642,633$, $615,546,531 ;{ }^{1} \mathrm{H}$ NMR (500 MHz, DMSO- $\left.d_{6}\right) \delta 2.07(3 \mathrm{H}$, s), $5.22(2 \mathrm{H}, \mathrm{s}), 7.33(2 \mathrm{H}, \mathrm{d}, J 8.8 \mathrm{~Hz}), 7.81-7.84(3 \mathrm{H}, \mathrm{m})$, $7.88(1 \mathrm{H}, \mathrm{td}, J 1.3$ and $7.5 \mathrm{~Hz}), 8.05-8.06(1 \mathrm{H}, \mathrm{m}), 8.06-8.07$ $(1 \mathrm{H}, \mathrm{m}), 8.74(1 \mathrm{H}, \mathrm{s}), 9.29(1 \mathrm{H}, \mathrm{s}) ;{ }^{13} \mathrm{C} \mathrm{NMR}(75 \mathrm{MHz}$, DMSO- $\left.d_{6}\right) \delta 21.0,57.4,116.9,120.5,123.1,124.9,126.6$, $127.0,130.9,132.4,133.0,133.8,135.2,140.1,143.5$, 143.6, 170.4, 177.2, 180.5; HRMS (ESI) $\mathrm{m} / z$, calcd. for $\mathrm{C}_{21} \mathrm{H}_{16} \mathrm{ClN}_{4} \mathrm{O}_{4}[\mathrm{M}+\mathrm{H}]^{+}$: 423.0860, found: 427.0860 .

2-Chloro-3-((3-(4-(phenoxymethyl)-1H-1,2,3-triazol-1-yl) phenyl)amino)naphthalene-1,4-dione (8k)

Orange solid, yield $55 \%$, mp $212-214{ }^{\circ} \mathrm{C}$; IR (KBr) $v / \mathrm{cm}^{-1} 3332,3076,2925,1664,1653,1574,1522,1496$, $1456,1445,1408,1326,1287,1236,1187,1176,1152$, $1135,1111,1083,1057,1044,1017,991,910,884,851$, 834, 809, 786, 749, 732, 715, 690, 680, 652, 628, 614, 535; ${ }^{1} \mathrm{H}$ NMR (500 MHz, DMSO- $\left.d_{6}\right) \delta 5.25(1 \mathrm{H}, \mathrm{s}), 6.96-6.99$ (2H, m), 7.30-7.35 (4H, m), 7.81-7.84 (3H, m), 8.05-8.06 $(1 \mathrm{H}, \mathrm{m}), 8.06-8.07(1 \mathrm{H}, \mathrm{m}), 8.83(1 \mathrm{H}, \mathrm{s}), 9.30(1 \mathrm{H}, \mathrm{s})$; ${ }^{13} \mathrm{C}$ NMR (75 MHz, DMSO- $\left.d_{6}\right) \delta 61.7,115.4,116.8,120.4$, $121.5,123.0,124.9,126.6,127.0,129.9,130.8,132.5$, $133.1,133.7,135.2,140.0,143.6,144.4,158.6,177.2$, 180.4; HRMS (ESI) $m / z$, calcd. for $\mathrm{C}_{25} \mathrm{H}_{17} \mathrm{ClN}_{4} \mathrm{O}_{3} \mathrm{Na}^{+}$ $[\mathrm{M}+\mathrm{Na}]^{+}:$479.0887, found: 479.0881 .

2-Chloro-3-((3-(4-(hydroxymethyl)-1H-1,2,3-triazol-1-yl) phenyl)amino)naphthalene-1,4-dione (9a)

Brown solid, yield 46\%, mp 220-222 ${ }^{\circ} \mathrm{C}$; IR (KBr) $v / \mathrm{cm}^{-1}$ 3248, 3145, 1672, 1636, 1594, 1570, 1504, 1443, 1332, 1287, 1239, 1209, 1165, 1138, 1088, 1045, 1027, 1005, $922,860,845,787,765,739,714,700,685,659,611,595$, $571 ;{ }^{1} \mathrm{H}$ NMR $\left(500 \mathrm{MHz}, \mathrm{DMSO}-d_{6}\right) \delta 4.62(2 \mathrm{H}, \mathrm{d}, J 5.4 \mathrm{~Hz})$, $5.14(1 \mathrm{H}, \mathrm{s}), 7.23-7.26(1 \mathrm{H}, \mathrm{m}), 7.51(1 \mathrm{H}, \mathrm{t}, J 8.0 \mathrm{~Hz}), 7.62-$ $7.64(1 \mathrm{H}, \mathrm{m}), 7.67(1 \mathrm{H}, \mathrm{t}, J 2.0 \mathrm{~Hz}), 7.83(1 \mathrm{H}, \mathrm{td}, J 1.3$ and $7.5 \mathrm{~Hz}), 7.88(1 \mathrm{H}, \mathrm{td}, J 1.3$ and $7.5 \mathrm{~Hz}), 8.05-8.08(2 \mathrm{H}, \mathrm{m})$, $8.53(1 \mathrm{H}, \mathrm{s}), 9.28(1 \mathrm{H}, \mathrm{s}) ;{ }^{13} \mathrm{C} \mathrm{NMR}\left(75 \mathrm{MHz}, \mathrm{DMSO}-d_{6}\right) \delta$ 55.5, 115.3, 115.8, 117.3, 121.3, 123.6, 126.6, 127.0, 129.8, 130.9, 132.4, 133.8, 135.2, 137.0, 141.1, 143.5, 149.6, 177.3, 180.4; HRMS (ESI) $m / z$, calcd. for $\mathrm{C}_{19} \mathrm{H}_{12} \mathrm{ClN}_{4} \mathrm{O}_{3}[\mathrm{M}+\mathrm{H}]^{+}$: 381.0754, found: 381.0752 .

2-Chloro-3-((3-(4-(2-hydroxyethyl)-1H-1,2,3-triazol-1-yl) phenyl)amino)naphthalene-1,4-dione (9b)

Orange solid, yield $31 \%$, mp 204-206 ${ }^{\circ} \mathrm{C}$; IR (KBr) $v / \mathrm{cm}^{-1} 3247,3146,2959,2924,1672,1635,1593,1569$, $1504,1445,1374,1334,1289,1238,1202,1173,1139$, 1091, 1049, 1001, 923, 860, 836, 788, 737, 716, 684, 643, 612, 594, 569; ${ }^{1} \mathrm{H}$ NMR (500 MHz, DMSO- $\left.d_{6}\right) \delta 2.87(2 \mathrm{H}$, t, J $6.8 \mathrm{~Hz}), 3.72(2 \mathrm{H}, \mathrm{t}, J 6.8 \mathrm{~Hz}), 4.57(1 \mathrm{H}, \mathrm{s}), 7.50(1 \mathrm{H}$, $\mathrm{t}, J 8.0 \mathrm{~Hz}), 7.59-7.61(1 \mathrm{H}, \mathrm{m}), 7.65(1 \mathrm{H}, \mathrm{t}, J 2.0 \mathrm{~Hz}), 7.82$ $(1 \mathrm{H}, \mathrm{td}, J 1.3$ and $7.5 \mathrm{~Hz}), 7.88(1 \mathrm{H}, \mathrm{td}, J 1.3$ and $7.5 \mathrm{~Hz})$, 8.05-8.07 (2H, m), $8.42(1 \mathrm{H}, \mathrm{s}), 9.27(1 \mathrm{H}, \mathrm{s}) ;{ }^{13} \mathrm{C} \mathrm{NMR}$ $\left(125 \mathrm{MHz}, \mathrm{DMSO}-d_{6}\right) \delta 29.6,60.7,115.3,115.8,117.0$, $121.1,123.6,126.6,127.0,129.8,130.9,132.4,133.8$, 135.2, 137.1, 141.0, 143.5, 146.2, 177.3, 180.4; HRMS (ESI) $m / z$, calcd. for $\mathrm{C}_{20} \mathrm{H}_{16} \mathrm{ClN}_{4} \mathrm{O}_{3}[\mathrm{M}+\mathrm{H}]^{+}:$395.0911, found: 395.0910 .

2-((3-(4-Butyl-1H-1,2,3-triazol-1-yl)phenyl)amino)-3-chloronaphthalene-1,4-dione (9c)

Black solid, yield $56 \%$, mp $181-183{ }^{\circ} \mathrm{C}$; IR (KBr) $v / \mathrm{cm}^{-1}$ 3340, 2930, 2237, 2182, 2159, 2021, 2004, 1982, 1669, 1647, 1592, 1569, 1493, 1464, 1328, 1285, 1260, 
$1238,1222,1158,1134,1095,1044,1020,1004,918$, $862,828,785,682,597,574,550 ;{ }^{1} \mathrm{H}$ NMR $(500 \mathrm{MHz}$, DMSO- $\left.d_{6}\right) \delta 0.93(3 \mathrm{H}, \mathrm{t}, J 7.4 \mathrm{~Hz}), 1.38(2 \mathrm{H}, \mathrm{sex}, J 7.4 \mathrm{~Hz})$, $1.66(2 \mathrm{H}$, quin, $J 7.4 \mathrm{~Hz}), 2.71(2 \mathrm{H}, \mathrm{t}, J 7.4 \mathrm{~Hz}), 7.21-7.23$ $(1 \mathrm{H}, \mathrm{m}), 7.50(1 \mathrm{H}, \mathrm{t}, J 8.0 \mathrm{~Hz}), 7.59-7.61(1 \mathrm{H}, \mathrm{m}), 7.65$ $(1 \mathrm{H}, \mathrm{t}, J 2.0 \mathrm{~Hz}), 7.82(1 \mathrm{H}, \mathrm{td}, J 1.3$ and $7.5 \mathrm{~Hz}), 7.88(1 \mathrm{H}$, td, $J 1.3$ and $7.5 \mathrm{~Hz}), 8.05-8.08(2 \mathrm{H}, \mathrm{m}), 8.42(1 \mathrm{H}, \mathrm{s}), 9.27$ $(1 \mathrm{H}, \mathrm{s}) ;{ }^{13} \mathrm{C}$ NMR $\left(75 \mathrm{MHz}\right.$, DMSO- $\left.d_{6}\right) \delta 13.2,21.3,24.3$, 30.6, 114.5, 115.0, 116.3, 119.6, 122.8, 125.9, 126.2, 129.0, 130.2, 131.7, 133.0, 134.4, 136.4, 140.3, 142.8, 147.9, 176.5, 179.6; HRMS (ESI) $\mathrm{m} / z$, calcd. for $\mathrm{C}_{22} \mathrm{H}_{20} \mathrm{ClN}_{4} \mathrm{O}_{2}$ $[\mathrm{M}+\mathrm{H}]^{+}:$407.1275, found: 407.1259.

2-Chloro-3-((3-(4-(1-hydroxyethyl)-1H-1,2,3-triazol-1-yl) phenyl)amino)naphthalene-1,4-dione (9d)

Orange solid, yield $40 \%$, mp 191-193 ${ }^{\circ} \mathrm{C}$; IR (KBr) $v / \mathrm{cm}^{-1} 3252,3143,2923,2852,1671,1638,1593,1570$, 1504, 1459, 1442, 1372, 1331, 1256, 1238, 1162, 1136, 1094, 1048, 1008, 922, 884, 858, 834, 787, 742, 714, 685, $654,611,570 ;{ }^{1} \mathrm{H}$ NMR $\left(500 \mathrm{MHz}, \mathrm{DMSO}-d_{6}\right) \delta 1.48(3 \mathrm{H}$, d, $J 6.1 \mathrm{~Hz}), 2.54(1 \mathrm{H}, \mathrm{s}), 4.92(1 \mathrm{H}, \mathrm{q}, J 6.1 \mathrm{~Hz}), 7.24(1 \mathrm{H}$, dd, $J 1.2$ and $8.0 \mathrm{~Hz}), 7.50(1 \mathrm{H}, \mathrm{t}, J 8.0 \mathrm{~Hz}), 7.64(1 \mathrm{H}, \mathrm{dd}$, $J 1.2$ and $8.0 \mathrm{~Hz}), 7.67(1 \mathrm{H}, \mathrm{t}, J 2.0 \mathrm{~Hz}), 7.82(1 \mathrm{H}, \mathrm{td}, J 1.3$ and $7.5 \mathrm{~Hz}), 7.88(1 \mathrm{H}, \mathrm{td}, J 1.3$ and $7.5 \mathrm{~Hz}), 8.05-8.08$ $(2 \mathrm{H}, \mathrm{m}), 8.48(1 \mathrm{H}, \mathrm{s}), 9.28(1 \mathrm{H}, \mathrm{s}) ;{ }^{13} \mathrm{C}$ NMR $(75 \mathrm{MHz}$, DMSO- $\left.d_{6}\right) \delta 23.3,61.5,114.6,115.0,116.4,119.1,122.8$, $125.9,126.2,129.0,130.2,131.7,133.0,134.4,136.3$, 140.3, 142.8, 153.5, 176.6, 179.7; HRMS (ESI) $\mathrm{m} / \mathrm{z}$, calcd. for $\mathrm{C}_{20} \mathrm{H}_{16} \mathrm{ClN}_{4} \mathrm{O}_{3}[\mathrm{M}+\mathrm{H}]^{+}$: 395.0911, found: 395.0910 .

2-Chloro-3-((3-(4-(2-hydroxybutan-2-yl)-1H-1,2,3-triazol1-yl)phenyl)amino)naphthalene-1,4-dione (9e)

Red solid, yield $34 \%$, mp $198-200^{\circ} \mathrm{C}$; IR (KBr) $v / \mathrm{cm}^{-1}$ $3280,2963,2924,2112,1678,1634,1595,1566,1519$, 1504, 1440, 1372, 1339, 1288, 1241, 1229, 1174, 1137, 1083, 1043, 1016, 1003, 923, 862, 827, 808, 799, 791, 721, $690,633,600,571,534 ;{ }^{1} \mathrm{H}$ NMR $\left(500 \mathrm{MHz}\right.$, DMSO- $\left.d_{6}\right)$ $\delta 0.81(3 \mathrm{H}, \mathrm{t}, J 7.4 \mathrm{~Hz}), 1.79-1.86(1 \mathrm{H}, \mathrm{m}), 7.22-7.24(1 \mathrm{H}$, m), $7.50(1 \mathrm{H}, \mathrm{t}, J 8.0 \mathrm{~Hz}), 7.64-7.65(1 \mathrm{H}, \mathrm{m}), 7.68(1 \mathrm{H}$, $\mathrm{t}, J 2.0 \mathrm{~Hz}), 7.82(1 \mathrm{H}, \mathrm{td}, J 1.3$ and $7.5 \mathrm{~Hz}), 7.88(1 \mathrm{H}, \mathrm{td}$, $J 1.3$ and $7.5 \mathrm{~Hz}), 8.05-8.08(2 \mathrm{H}, \mathrm{m}), 8.41(1 \mathrm{H}, \mathrm{s}), 9.28$ $(1 \mathrm{H}, \mathrm{s}) ;{ }^{13} \mathrm{C}$ NMR $\left(75 \mathrm{MHz}, \mathrm{DMSO}-d_{6}\right) \delta 8.2,28.0,35.2$, 69.7, 108.9, 114.6, 115.1, 116.4, 123.0, 119.3, 126.1, $126.5,129.3,130.3,131.8,133.3,134.7,136.5,140.5$, 143.0, 155.9, 176.8, 179.9; HRMS (ESI) $\mathrm{m} / z$, calcd. for $\mathrm{C}_{22} \mathrm{H}_{19} \mathrm{ClN}_{4} \mathrm{O}_{3} \mathrm{Na}^{+}[\mathrm{M}+\mathrm{Na}]^{+}: 445.1044$, found: 445.1034 .

2-Chloro-3-((3-(4-(2-hydroxypropan-2-yl)-1H-1,2,3-triazol1-yl)phenyl)amino)naphthalene-1,4-dione (9f)

Red solid, yield $40 \%$, mp $192-194{ }^{\circ} \mathrm{C}$; IR (KBr) $v / \mathrm{cm}^{-1}$ 3287, 2964, 1676, 1636, 1594, 1567, 1521, 1505, 1436,
$1375,1362,1337,1287,1239,1211,1165,1136,1082$, $1047,1020,1005,978,962,921,895,862,826,808,740$, 685, 633, 600, 570, 534; ${ }^{1} \mathrm{H}$ NMR (500 MHz, DMSO- $d_{6}$ ) $\delta 1.54(6 \mathrm{H}, \mathrm{s}), 5.06(1 \mathrm{H}, \mathrm{s}), 7.24(1 \mathrm{H}, \mathrm{dd}, J 1.2$ and $8.0 \mathrm{~Hz})$, $7.50(1 \mathrm{H}, \mathrm{t}, J 8.0 \mathrm{~Hz}), 7.63-7.65(1 \mathrm{H}, \mathrm{m}), 7.67(1 \mathrm{H}, \mathrm{t}$, $J 2.0 \mathrm{~Hz}), 7.82(1 \mathrm{H}, \mathrm{td}, J 1.3$ and $7.5 \mathrm{~Hz}), 7.88(1 \mathrm{H}$, td, $J 1.3$ and $7.5 \mathrm{~Hz}), 8.06-8.07(1 \mathrm{H}, \mathrm{m}), 8.07-8.08(1 \mathrm{H}, \mathrm{m})$, $8.43(1 \mathrm{H}, \mathrm{s}), 9.28(1 \mathrm{H}, \mathrm{s}) ;{ }^{13} \mathrm{C}$ NMR $\left(75 \mathrm{MHz}\right.$, DMSO- $\left.d_{6}\right)$ $\delta 31.0,67.5,115.3,115.8,117.1,119.1,123.6,126.6$, 127.0, 129.8, 130.9, 132.4, 133.8, 135.2, 137.1, 141.0, 143.6, 157.4, 177.3, 180.4; HRMS (ESI) $\mathrm{m} / z$, calcd. for $\mathrm{C}_{21} \mathrm{H}_{18} \mathrm{ClN}_{4} \mathrm{O}_{3}[\mathrm{M}+\mathrm{H}]^{+}:$409.1067, found: 409.1071.

2-Chloro-3-((3-(4-pentyl-1H-1,2,3-triazol-1-yl)phenyl)amino) naphthalene-1,4-dione $\mathbf{( 9 g})$

Brown solid, yield $48 \%$, mp $180-182{ }^{\circ} \mathrm{C}$; IR (KBr) $v / \mathrm{cm}^{-1} 3342,3127,3081,2955,2928,2853,1670,1648$, 1594, 1575, 1513, 1493, 1465, 1377, 1329, 1289, 1258, $1239,1216,1157,1134,1091,1044,1020,863,786,748$, $714,682,650,634,597,575,532 ;{ }^{1} \mathrm{H}$ NMR $(500 \mathrm{MHz}$, DMSO- $\left.d_{6}\right) \delta 0.88(3 \mathrm{H}, \mathrm{t}, J 7.4 \mathrm{~Hz}), 1.33-1.36(4 \mathrm{H}, \mathrm{m})$, $1.68(2 \mathrm{H}$, quint, $J 7.4 \mathrm{~Hz}), 2.70(2 \mathrm{H}, \mathrm{t}, J 7.4 \mathrm{~Hz}), 7.22$ $(1 \mathrm{H}, \mathrm{dd}, J 1.8$ and $8.0 \mathrm{~Hz}), 7.50(1 \mathrm{H}, \mathrm{t}, J 8.0 \mathrm{~Hz}), 7.59-$ $7.61(1 \mathrm{H}, \mathrm{m}), 7.65(1 \mathrm{H}, \mathrm{t}, J 2.0 \mathrm{~Hz}), 7.82(1 \mathrm{H}, \mathrm{td}, J 1.3$ and $7.5 \mathrm{~Hz}), 7.88(1 \mathrm{H}, \mathrm{td}, J 1.3$ and $7.5 \mathrm{~Hz}), 8.05-8.08$ $(2 \mathrm{H}, \mathrm{m}), 8.42(1 \mathrm{H}, \mathrm{s}), 9.28(1 \mathrm{H}, \mathrm{s}) ;{ }^{13} \mathrm{C}$ NMR $(75 \mathrm{MHz}$, DMSO- $\left.d_{6}\right) \delta 14.2,22.3,25.3,28.9,31.1,115.3,115.7$, 117.1, 120.4, 123.6, 126.6, 127.0, 129.7, 130.9, 132.4, 133.8, 135.2, 137.1, 141.1, 143.6, 148.6, 177.3, 180.4; HRMS (ESI) $m / z$, calcd. for $\mathrm{C}_{23} \mathrm{H}_{22} \mathrm{ClN}_{4} \mathrm{O}_{2}[\mathrm{M}+\mathrm{H}]^{+}$: 421.1431, found: 421.1411 .

2-Chloro-3-((3-(4-hexyl-1H-1,2,3-triazol-1-yl)phenyl)amino) naphthalene-1,4-dione $(\mathbf{9 h})$

Red solid, yield 70\%, mp 186-188 ${ }^{\circ} \mathrm{C}$; IR (KBr) $v / \mathrm{cm}^{-1}$ 3342, 3127, 3082, 2954, 2922, 2852, 1730, 1670, 1649, $1595,1577,1515,1493,1465,1329,1289,1240,1211$, 1156, 1135, 1095, 1045, 1021, 1008, 970, 916, 864, 829, 786, 725, 714, 683, 649, 634, 597, 575, 532; ${ }^{1} \mathrm{H}$ NMR $\left(500 \mathrm{MHz}, \mathrm{DMSO}-d_{6}\right) \delta 0.88(3 \mathrm{H}, \mathrm{t}, J 7.4 \mathrm{~Hz}), 1.27-1.38$ $(6 \mathrm{H}, \mathrm{m}), 1.67(2 \mathrm{H}$, quint, $J 7.4 \mathrm{~Hz}), 2.70(2 \mathrm{H}, \mathrm{t}, J 7.4 \mathrm{~Hz})$, 7.21-7.23 $(1 \mathrm{H}, \mathrm{m}), 7.50(1 \mathrm{H}, \mathrm{t}, J 8.0 \mathrm{~Hz}), 7.59-7.61(1 \mathrm{H}$, $\mathrm{m}), 7.64(1 \mathrm{H}, \mathrm{t}, J 2.0 \mathrm{~Hz}), 7.82(1 \mathrm{H}, \mathrm{td}, J 1.3$ and $7.5 \mathrm{~Hz})$, $7.88(1 \mathrm{H}, \mathrm{td}, J 1.3$ and $7.5 \mathrm{~Hz}), 8.05-8.08(2 \mathrm{H}, \mathrm{m}), 8.42$ $(1 \mathrm{H}, \mathrm{s}), 9.28(1 \mathrm{H}, \mathrm{s}) ;{ }^{13} \mathrm{C}$ NMR $\left(125 \mathrm{MHz}, \mathrm{DMSO}-d_{6}\right)$ $\delta$ 14.2, 22.3, 25.4, 28.6, 29.1, 31.4, 115.2, 115.8, 116.9, $120.4,123.6,126.6,127.0,129.8,130.8,132.3,133.8$, 135.2, 137.1, 140.9, 143.5, 148.7, 177.3, 180.3; HRMS (ESI) $\mathrm{m} / z$, calcd. for $\mathrm{C}_{24} \mathrm{H}_{24} \mathrm{ClN}_{4} \mathrm{O}_{2}[\mathrm{M}+\mathrm{H}]^{+}: 435.1588$, found: 435.1585 . 
2-Chloro-3-((3-(4-(((tetrahydro-2H-pyran-2-yl)oxy)methyl)1H-1,2,3-triazol-1-yl)phenyl)amino)naphthalene-1,4-dione (9i)

Orange solid, yield $38 \%$, mp $154-156{ }^{\circ} \mathrm{C}$; IR (KBr) $v / \mathrm{cm}^{-1} 3341,2924,2850,1670,1648,1593,1574,1513$, 1494, 1466, 1328, 1288, 1239, 1200, 1132, 1078, 1035, 972, 904, 863, 828, 787, 733, 714, 683, 649, 633, 598, 574,$531 ;{ }^{1} \mathrm{H}$ NMR $\left(500 \mathrm{MHz}, \mathrm{DMSO}-d_{6}\right) \delta$ 1.47-1.55 $(4 \mathrm{H}, \mathrm{m}), 1.61-1.76(2 \mathrm{H}, \mathrm{m}), 3.47-3.51(1 \mathrm{H}, \mathrm{m}), 3.80-3.85$ $(1 \mathrm{H}, \mathrm{m}), 4.62(1 \mathrm{H}, \mathrm{d}, J 12.5 \mathrm{~Hz}), 4.75(1 \mathrm{H}, \mathrm{t}, J 3.8 \mathrm{~Hz})$, $4.78(1 \mathrm{H}, \mathrm{d}, J 12.5 \mathrm{~Hz}), 7.24-7.26(1 \mathrm{H}, \mathrm{m}), 7.51(1 \mathrm{H}, \mathrm{t}$, $J 8.0 \mathrm{~Hz}), 7.63-7.65(1 \mathrm{H}, \mathrm{m}), 7.69(1 \mathrm{H}, \mathrm{t}, J 2.0 \mathrm{~Hz}), 7.82$ $(1 \mathrm{H}, \mathrm{td}, J 1.3$ and $7.5 \mathrm{~Hz}), 7.88(1 \mathrm{H}, \mathrm{td}, J 1.3$ and $7.5 \mathrm{~Hz})$, 8.05-8.07 (2H, m), $8.65(1 \mathrm{H}, \mathrm{s}), 9.29(1 \mathrm{H}, \mathrm{s}) ;{ }^{13} \mathrm{C} \mathrm{NMR}$ $\left(75 \mathrm{MHz}\right.$, DMSO- $\left.d_{6}\right) \delta 19.4,25.4,30.5,59.9,61.8,97.7$, $115.3,115.8,117.1,122.6,123.7,126.6,127.0,129.8$, 130.9, 132.3, 133.8, 135.2, 136.8, 141.0, 143.5, 145.6, 177.3, 180.4; HRMS (ESI) $\mathrm{m} / z$, calcd. for $\mathrm{C}_{24} \mathrm{H}_{22} \mathrm{ClN}_{4} \mathrm{O}_{4}$ $[\mathrm{M}+\mathrm{H}]^{+}:$465.1329, found: 465.1309 .

2-Chloro-3-((3-(4-propyl-1H-1,2,3-triazol-1-yl)phenyl)amino) naphthalene-1,4-dione (9j)

Brown solid, yield $38 \%$, mp $187-189{ }^{\circ} \mathrm{C}$; IR (KBr) $v / \mathrm{cm}^{-1} 3340,2960,2928,1670,1648,1593,1574,1513$, $1493,1465,1328,1288,1238,1194,1157,1133,1046$, 1020, 1004, 916, 863, 828, 786, 734, 714, 683, 633, 598, 574, 531; ${ }^{1} \mathrm{H}$ NMR (500 MHz, DMSO- $\left.d_{6}\right) \delta 0.96(3 \mathrm{H}, \mathrm{t}$, $J 7.4 \mathrm{~Hz}), 1.69(2 \mathrm{H}, \mathrm{q}, J 7.4 \mathrm{~Hz}), 2.68(2 \mathrm{H}, \mathrm{t}, J 7.4 \mathrm{~Hz})$, $7.22(1 \mathrm{H}, \mathrm{dd}, J 1.8$ and $8.0 \mathrm{~Hz}), 7.50(1 \mathrm{H}, \mathrm{t}, J 8.0 \mathrm{~Hz}), 7.60-$ $7.62(1 \mathrm{H}, \mathrm{m}), 7.66(1 \mathrm{H}, \mathrm{t}, J 2.0 \mathrm{~Hz}), 7.82(1 \mathrm{H}, \mathrm{td}, J 1.3$ and $7.5 \mathrm{~Hz}), 7.88(1 \mathrm{H}, \mathrm{td}, J 1.3$ and $7.5 \mathrm{~Hz}), 8.05-8.07(1 \mathrm{H}, \mathrm{m})$, 8.04-8.05 (1H, m), $8.41(1 \mathrm{H}, \mathrm{s}), 9.27(1 \mathrm{H}, \mathrm{s}) ;{ }^{13} \mathrm{C} \mathrm{NMR}$ $\left(75 \mathrm{MHz}, \mathrm{DMSO}-d_{6}\right) \delta 14.0,22.5,27.5,115.1,115.6$, $116.9,120.5,123.5,126.6,127.0,129.8,130.9,132.3$, 133.8, 135.2, 137.0, 141.0, 143.5, 148.4, 177.3, 180.4; HRMS (ESI) $m / z$, calcd. for $\mathrm{C}_{21} \mathrm{H}_{17} \mathrm{ClN}_{4} \mathrm{O}_{2} \mathrm{Na}[\mathrm{M}+\mathrm{Na}]^{+}$: 415.0938, found: 415.0916 .

\section{Biological assays}

\section{Solubilization and dilution}

The synthetic compounds were solubilized first in DMSO $100 \%$, and then diluted in distilled water, for 1.5 and $40 \mathrm{mg} \mathrm{mL}^{-1}$ concentrations, respectively. After dilution, the compounds were immediately used and later stored in $\mathrm{a}-20{ }^{\circ} \mathrm{C}$ freezer.

\section{Bacterial strain}

The bacterial strain used was CCT 3440 because its cultivation is done in a simplified way and in aerobiosis was donated by The Collection of Reference Microorganisms in Sanitary Surveillance (CMRVS) and Dr Ivano de Filippis of the National Institute of Quality Control in Health (INCQS), Oswaldo Cruz Foundation (FIOCRUZ).

\section{Bacterial resuspension}

The culture media used were sterilized before use and were evaluated by bacterial growth test and Gram, ensuring that the media is sterile. The resuspension was made according to that provided by the FIOCRUZ, POP INCQS number: 65.3230.006-attachment E-Rev 05, classification 544.2, described below. The end of the recipient was broken. Then, with a Pasteur pipet, 0.2$0.5 \mathrm{~mL}$ of the medium Brain Heart Infusion (BHI) was inoculated to solubilize the bacteria. The homogenized solution was moved into a cell culture bottle, which went to a bacteriological incubator for $24 \mathrm{~h}$ under the conditions of $37^{\circ} \mathrm{C}$ and $5 \%$ of $\mathrm{CO}_{2}$. At the end of this time, the bottle was moved to a freezer.

\section{Antibiogram preparation}

Müller-Hinton agar was prepared in proportion according to the manufacturer's recommendation. This medium was then poured in Petri dishes, which were placed under ultraviolet light to solidify.

The sterile disk diffusion was placed in an apparatus and received the desired doses of evaluation. They were 15 and $300 \mu \mathrm{g}$ for each synthetic compound, and the same for the streptomycin control (the $300 \mu \mathrm{g}$ dose contained pre-prepared disks from the Specialized Microbiological Diagnostics-DME).

In a cleanroom, the antibiogram was performed near a Bunsen burner. The bacteria in the $0.5 \mathrm{McF}$ arland scale $\left(1.5 \times 10^{8} \mathrm{CFU} \mathrm{mL} \mathrm{mL}^{-1}\right.$, where $\mathrm{CFU}$ is colony forming unit) were seeded in all the Petri dish plates. The disks with the doses to be evaluated were placed in the periphery of the plate, and the control in the middle. The plates were moved to the bacteriological incubator for $24 \mathrm{~h}$ in the same conditions described above. After this time, they were observed to determine if any compound inhibits the bacterial growth and the halo of inhibition was measured. This experiment was performed in triplicate.

The statistical analysis performed was a one-way analysis of variance (ANOVA) followed by Tukey's test, using the GraphPad Prism 8 program. ${ }^{22}$ For the comparison between two doses $(15$ and $300 \mu \mathrm{g})$ tested for the same compound, an unpaired $t$-test was used.

\section{Minimum inhibitory concentration (MIC)}

The BHI medium was prepared according to the manufacturers' recommendations and taken to be autoclaved at $121{ }^{\circ} \mathrm{C}$ for $15 \mathrm{~min}$. 96-well plates were made, receiving $200 \mu \mathrm{L}$ as the final volume used in each 
well. Each used well, except the negative control, also received $1 \mu \mathrm{L}$ of a solution containing bacteria in the 0.5 McFarland scale. The curve of concentration test used for the treatment were $2.5,5.0,10.0,15.0,30.0 \mu \mathrm{g} \mathrm{mL}^{-1}$. The plates were taken to a bacteriological incubator for $24 \mathrm{~h}$ in the conditions described above. At the end of this time, one representative drop was removed from each well and placed in different Petri dishes. They were taken again to the incubator for more than $24 \mathrm{~h}$ under the same conditions. After this time, they were observed for any bacterial growth. If there was not in some concentration, then it was considered as the MIC.

\section{Cytotoxicity assay}

The cytotoxicity test was performed previously by our research group, using the 3-(4,5-dimethylthiazole-2-yl)2,5-diphenylthetrazolium bromide (MTT) methodology. ${ }^{23}$ Vero cells were seeded in 96-well plates, with a density of $1 \times 10^{4}$ cells per well, and treated with doses of 50, 100, $200,400,800$ and $1000 \mu \mathrm{gL}^{-1}$ for synthetic compounds, maintained cell viability above $80 \%$, then taken to a cell culture incubator for $72 \mathrm{~h}$ at $37^{\circ} \mathrm{C}$ in a humid atmosphere with $5 \% \mathrm{CO}_{2}$. After that time, the medium with the substances was removed to add $50 \mu \mathrm{L}$ of the MTT solution (Sigma-Aldrich, São Paulo, Brazil) at a concentration of $5 \mathrm{mg} \mathrm{mL}^{-1}$ and incubated for $4 \mathrm{~h}$ at the conditions described above. At the end, the medium was removed, and $100 \mu \mathrm{L}$ of DMSO was added to each well to dissolve formazan crystals. The optical density was determined in a plate reader at $545 \mathrm{~nm}$, and the cell viability was calculated by comparing the treated and untreated values. All experiments were carried out in triplicate.

\section{Acute toxicity}

\section{Animals}

Female BALB/c mice, weighing 20 to $30 \mathrm{~g}$, with two months of life were used. These animals were raised and kept at Universidade Federal Fluminense (UFF), having been approved by No. 798 of the Ethics Committee on the Use of Animals of the Pro-Rectory of Research, Postgraduate and Innovation of the referred university.

The animals were housed in three groups of five animals each (A1, A2, A3, A4 and A5). Group 1 (G1), represented by animals that received the synthetic substance 9i diluted in DMSO 1\%, group 2 (G2), animals that received DMSO 1\% (vehicle) and group 3 (G3), animals that received saline.

The animals remained in polyethylene cages with wire lids, measuring about $30 \times 20 \times 13 \mathrm{~cm}$. The mice were housed in environments like: a 12/12 h light and dark cycle, at a controlled temperature of 22 to $24^{\circ} \mathrm{C}$, receiving basic food from commercial feed and filtered water and treated with $\mathrm{HCl}$ (hydrochloric acid) at $0.1 \%$ ad libitum provided by the university.

Throughout the experiment, which lasted 14 days, behavioral aspects of the animals were observed, such as: bristling of the hair, tachycardia, stretching of the hind legs (pain symptom), apathy, and hyperesthesia of the tail. The weights of the mice were observed and recorded during the 14 consecutive days of the trial.

\section{Administration}

To determine the acute toxicity of the synthetic substance 9i, the OECD chemical testing guides ${ }^{24}$ were used, with some modifications. BALB/c mice were used, in which substances diluted with $1 \%$ DMSO was administered in the group: 9i at a dose of $175 \mathrm{mg} \mathrm{kg}^{-1}$ and two control groups: one with saline solution (control) and the other with $1 \%$ DMSO (vehicle). The dose applied with the $9 \mathbf{i}$ was lower due to the low $50 \%$ cytotoxic concentration $\left(\mathrm{CC}_{50}\right)$ of the $9 \mathbf{i}$. The administrations were made by single gavage on the first day of the experiment, in the amount of $200 \mu \mathrm{L}$. Blood and the organs were collected on the $14^{\text {th }}$ day after the administration of the substances.

\section{Biochemical assessment}

Blood samples were collected through the retroorbital procedure, and the animals were euthanized with ketamine associated with xylazine, at a dose of $90 \mathrm{mg} \mathrm{kg}^{-1}$ of ketamine weight and $10 \mathrm{mg} \mathrm{kg}^{-1}$ of xylazine weight, applied intraperitoneally.

These samples were collected in blood collection microtubes with separator gel in order to facilitate the separation of serum to be evaluated for the following parameters: urea $\left(\mathrm{mg} \mathrm{dL}^{-1}\right)$, creatinine $\left(\mathrm{mg} \mathrm{dL}^{-1}\right), \mathrm{TGO} / \mathrm{AST}$ (glutamic-transaminase-oxalacetic-IU L ${ }^{-1}$ ) and TGP/ALT (pyruvic glutamic transaminase-IU L ${ }^{-1}$ ). For the separation of the serum, the blood was centrifuged at $3500 \mathrm{rpm}$ for $30 \mathrm{~min}$. After being centrifuged, the serum was transferred to another test tube with the aid of an automatic pipette and stored $\left(-18^{\circ} \mathrm{C}\right)$ until the time of analysis.

Kits developed and standardized by BIOCLIN (Quibasa Química Básica LTDA, Belo Horizonte, Brazil) from the State of Rio de Janeiro were used and analyzed on the BS 120 (BIOCLIN) equipment for biochemistry. The analyses were carried out at the Experimental Nutrition Laboratory (LABNE) of this university.

\section{Histological analyses}

At the end of the experiment, the animals were euthanized by anesthetic overdose (ketamine/xylazine), 
and, in order to perform the histological analysis, the following organs were extracted: liver, spleen, kidney, brain, stomach, duodenum, and heart. The organs were fixed in Carson's formaldehyde (5\% buffered). Subsequently, fragments of the organs were removed and processed in the Lupe PT 05 histotechnical machine, undergoing gradual dehydration in alcohols (70, 90, 95 and $100 \%$ ), diaphanization in xylol, and impregnation in paraffin. The fragments were cut in a microtome $5 \mu \mathrm{m}$ dewaxed and stained with hematoxylin and eosin. After this processing, histological analysis was performed with the help of pathologist Dr Carla Eponina from the Laboratory of Experimental Pathology (LAPE), Department of Immunobiology at UFF.

\section{Data evaluation}

A quantitative-type methodology was used for the results obtained with the school's salivary exams (salivary electrical test and salivary $\mathrm{pH}$ ). The data were tabulated in a statistical program (EPI INFO $\left.{ }^{\text {TM }} 6.04\right)^{25}$ and presented descriptively. For statistical analysis of the laboratory part of the substances tested and in vivo tests of the animals used in the work, the results were described as means and standard deviations. The one-way ANOVA test was applied, with Dunnett's post-test comparing all verses to reference, at the level of $p<0.05$, using the GraphPad InStat ${ }^{\circledR}$ Program. ${ }^{26}$

\section{Results and Discussion}

\section{Chemistry}

Initially, from the nucleophilic aromatic substitution between phenylenediamine ( 2 or 3 ) and 2,3-dichloro- 1,4-naphtoquinone (1) we produced amino-quinones 4 (para isomer) and $\mathbf{5}$ (meta isomer) in good yields ( 85 and $72 \%$, respectively). Next, diazotization of anilines $\mathbf{4}$ and 5 by treatment with aqueous sodium nitrite followed by nucleophilic aromatic substitution in reaction with sodium azide led to the formation of azides $\mathbf{6}$ and $\mathbf{7}$. Then, without prior purification of $\mathbf{6}$ and 7, using the protocol based on a Huisgen 1,3-dipolar cycloaddition, we performed the reaction between the azido-naphthoquinones $\mathbf{6}$ and 7 and a correspondent alkyne catalyzed by $\mathrm{Cu}(\mathrm{I})$, led to 1,4-disubstituted regioisomer $\mathbf{8 a - 8} \mathbf{k}$ and $\mathbf{9 a - 9 j}$ (Scheme 1).

In general, we did not observe any significant influence of the $\mathrm{R}$ group in the phenyl ring on the yield of the reactions to obtain $\mathbf{8 a - 8 k}$ and $\mathbf{9 a - 9 j}$.

The compounds structures were confirmed by spectroscopic techniques (see Experimental and Supplementary Information (SI) sections). In the ${ }^{1} \mathrm{H}$ NMR spectrum analysis of compound $\mathbf{9 i}$, for example, it could be observed a triplet at $4.75 \mathrm{ppm}(1 \mathrm{H}, \mathrm{t}, J 3.8 \mathrm{~Hz})$ corresponding to anomeric hydrogen of furan group; it was also observed a singlet at $9.29 \mathrm{ppm}(1 \mathrm{H}, \mathrm{s})$ corresponding to aromatic hydrogen of triazolic ring. The signals at 177.3 and $180.4 \mathrm{ppm}$ in ${ }^{13} \mathrm{C}$ NMR corresponding to two carbonyls group confirm the coupling between 1,4-naphthoquinone and 1,2,3-triazole moieties.

\section{Biological assays}

Caries remains a global public health problem today, ${ }^{27}$ even with actions aimed at preventing it. ${ }^{7}$ This issue ends up impacting people's quality of life, including financial expenses, ${ }^{28,29}$ which leads to a search for new synthetic compounds and natural extracts that have an inhibiting
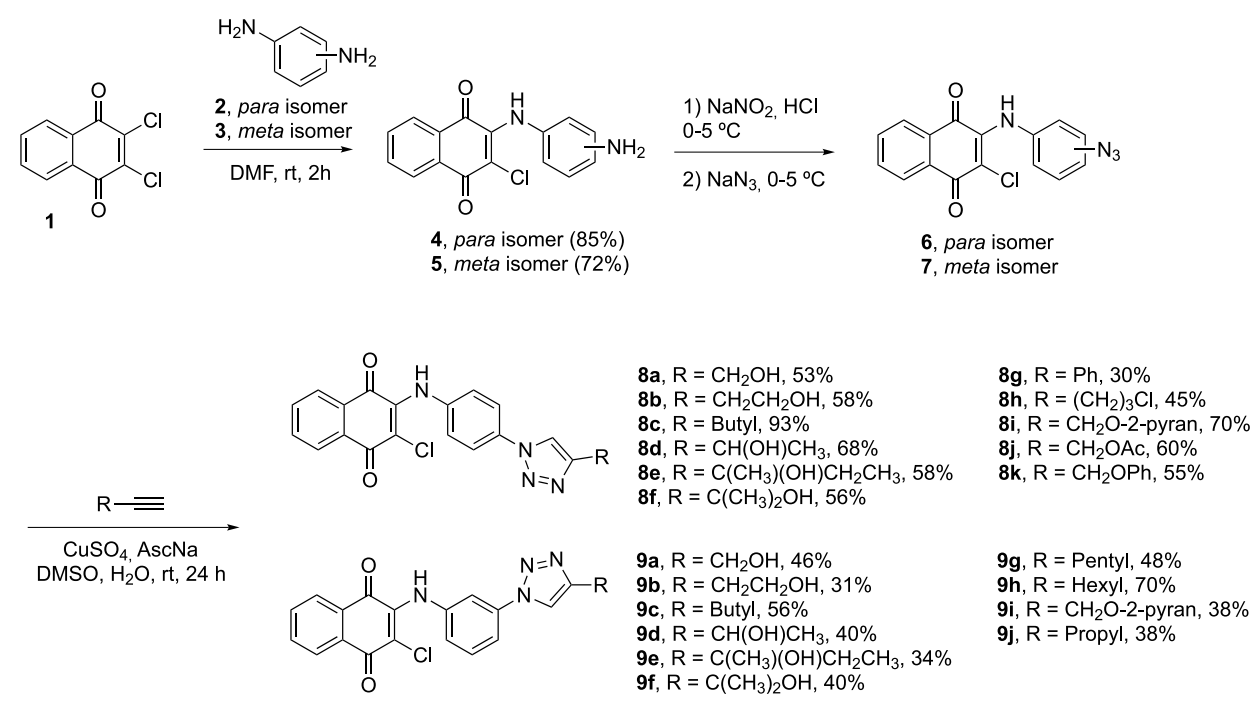

Scheme 1. Synthetic route for the synthesis of $\mathbf{8 a - 8} \mathbf{k}$ and $\mathbf{9 a - 9 j}$ 
effect on the multiplication of the main etiological agent of this dysbiosis, S. mutans.

S. mutans has been described as resistant to antibiotic aminoglycosides, including streptomycin. ${ }^{30-32}$ However, our data showed that this bacterium is not resistant to streptomycin, and this is demonstrated in other works, where the $S$. mutans did not show resistance to aminoglycosides, including to streptomycin. ${ }^{33-38}$

Also, our data demonstrate a strong sensibility of this bacteria to the synthetic compounds, in both doses (15 and $300 \mu \mathrm{g}$ ), since they behave similarly to the streptomycin control, an antibiotic of clinical use, in the antibiogram test. This inhibition is also observed at the MIC assay, where we found no growth of it in low doses, 5 and $10 \mu \mathrm{gL}^{-1}$. These promising results are also found in the scaffolds that gives our compounds' origin. To begin, it was described that derivatives of triazoles had strong results against Grampositive and negative bacteria. ${ }^{20,39,40}$ Besides that, low MIC values were also found, ranging from 1 to $10 \mu \mathrm{g} \mathrm{mL}{ }^{-1},{ }^{19} 9$ to $26 \mu \mathrm{g} \mathrm{mL}{ }^{-1}, 41$ and higher 16 to more than $512 \mu \mathrm{g} \mathrm{mL}$. $^{-38}$ Furthermore, good results of naphthoquinones were demonstrated against Gram-positive bacteria in the sensibility and MIC test, with data showing 7 to $13 \mathrm{~mm}$ of inhibition halo and MIC values of 32 to $256 \mu \mathrm{g} \mathrm{mL}{ }^{-1}{ }^{16}$ and other derivatives with inhibition zones ranging from 10 to $13 \mathrm{~mm}$, for Gram-positive bacteria. ${ }^{17}$

Our compounds showed results better than the single derivatives of naphthoquinones or triazoles supporting the idea that hybrid these molecules have a better effect than the nucleus that gives the origin of this hybrid structure. ${ }^{15}$ It is suggested that the biological activity of the compounds tested in the present study is similar to the mechanism of action observed in triazoles, which may occur due to interference in the cytochrome $\mathrm{P} 450$ pathway, ${ }^{42}$ involved in different important metabolic routes for bacteria. ${ }^{43} \mathrm{It}$ can also be similar to the mechanism of action described for naphthoquinones, promoting oxidative stress through the production of reactive oxygen species or interfering with the biological functions of topoisomerases I and II. ${ }^{13,18}$

From the twenty-one compounds evaluated, we observed that four of them were able to significantly inhibit the multiplication of $S$. mutans. In both doses, $15 \mu \mathrm{g}$ per disc and $300 \mu \mathrm{g}$ per disc, the synthetic molecules behaved similarly to the streptomycin control, which is a drug for clinical use. With no statistical difference as to the size of the inhibition halos (Figure 1), these results were evaluated as very promising. It is noteworthy that compounds $\mathbf{8 a - 8 k}$ and compounds 9a-9d, 9f and compound $9 \mathbf{g}$, had no effect on the multiplication of S. mutans. The DMSO, used as a control, showed no inhibition and was made on a separate plate. Statistical analysis performed was one-way ANOVA followed by the Tukey's test $(p<0.05)$, using GraphPad Prism $8 .{ }^{22}$

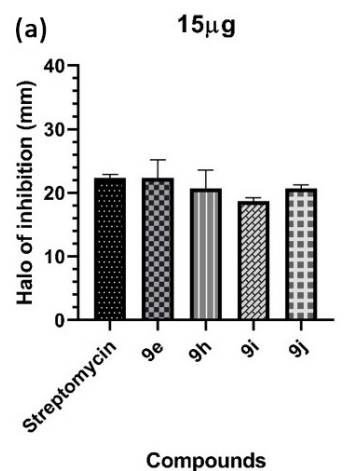

(c)

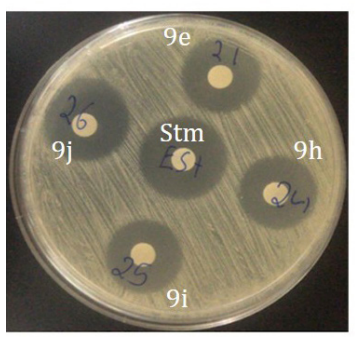

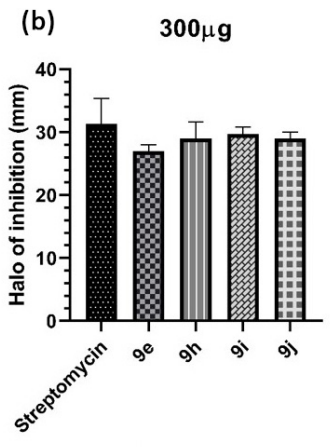

Compounds

(d)

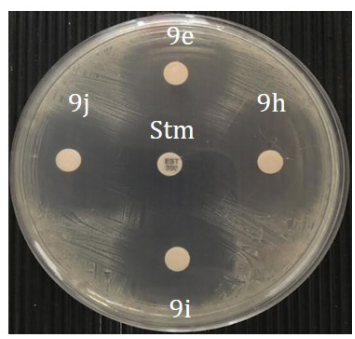

Figure 1. Antibiogram of doses of 15 and $300 \mu \mathrm{g}$ per disc (mm) of the synthetic compounds $9 \mathbf{e}, \mathbf{9 h}, \mathbf{9 i}$, and $\mathbf{9 j}$, which shows biological activity. (a) Average inhibition halos at the dosage of $15 \mu \mathrm{g}$ per disc. (b) The average of the inhibition halos at the dosage of $300 \mu \mathrm{g}$ per disc. (c) Plate representing the result of the antibiogram at the dosage of $15 \mu \mathrm{g}$ per disc. (d) Plate representing the result of the antibiogram at a dosage of $300 \mu \mathrm{g}$ per disc. ${ }^{*} p<0.05 . \mathrm{Stm}=$ streptomycin.

Concerning these same substances evaluated, a comparison was made between the averages of the halos of inhibition of the highest dose ( $300 \mu \mathrm{g}$ per disc) and the lowest dose $(15 \mu \mathrm{g}$ per disc) for each of the four molecules and the streptomycin control to see if the difference in dosages could imply variations in biological activity. It was observed that the compounds $9 \mathbf{i}$ and $\mathbf{9 j}$ showed high significance ( $p=0.0001$ and $p=0.0002$, respectively) $(* * *)$, while streptomycin and $\mathbf{9 h}$ showed a low significance ( $p=0.0188$ and $p=0.0211$, respectively) $\left(^{*}\right)$ and, finally, 9e does not present significance $(p=0.0572)$, indicating that the mean of the latter was not statistically different. This demonstrates that the substances $\mathbf{9 i}$ and $\mathbf{9 j}$ present an elevation of the inhibitory effect, as it increases the dose. This fact is also observed, in a tenuous way, with streptomycin and $\mathbf{9 h}$. Regarding the $\mathbf{9 e}$ molecule, there was no increase in inhibition with dose rise. The statistical test used was the unpaired $t$-test $(p<0.05)$ in the GraphPad Prism 8 program $^{22}$ (Figure 2).

In the minimum inhibitory concentration test, promising results were observed for these compounds, with MIC for 
9e and $9 \mathbf{h}$ at $10 \mu \mathrm{g} \mathrm{mL} L^{-1}$ and $\mathbf{9 i}$ and $\mathbf{9 j}$ at $5 \mu \mathrm{g} \mathrm{mL} L^{-1}$, the same being determined by the absence of bacterial growth, as demonstrated in Figure 3.
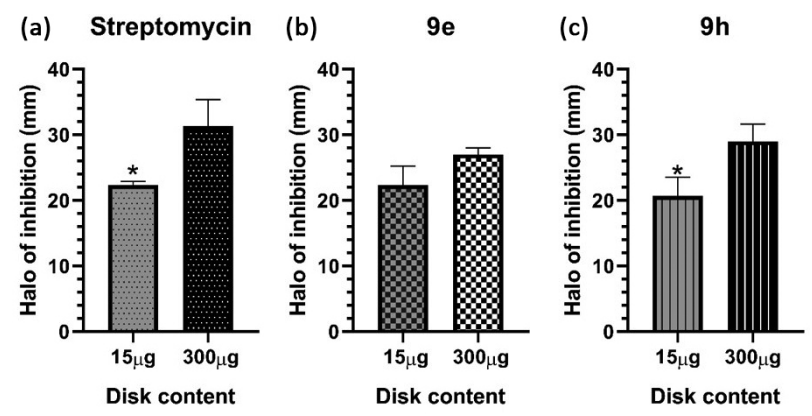

(d) $9 \mathrm{i}$
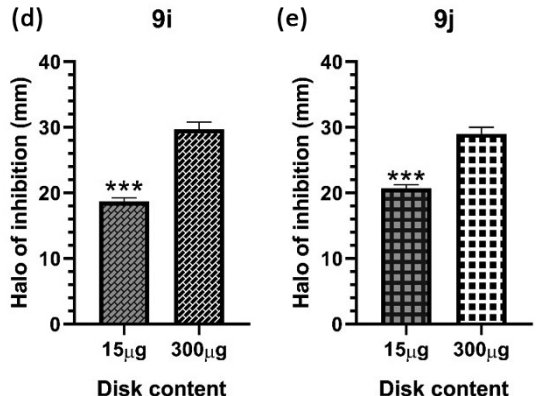

Figure 2. Comparison between the two dosages (300 and $15 \mu \mathrm{g}$ per disc) of each of the synthetic compounds that show biological activity $(\mathbf{9 e}, \mathbf{9 h}$, 9i, 9j). (a) Streptomycin showing low significance $\left({ }^{*} p=0.0188\right)$. (b) $9 \mathbf{e}$ not showing significance $(p=0.0572)$. (c) $9 \mathbf{h}$ showing low significance $(* p=0.0211)$. (d) $9 \mathbf{i}$ showing high significance $(* * * p=0.0001)$. (e) $9 \mathbf{j}$ showing high significance $(* * * p=0.0002) .{ }^{*} p<0.05$.
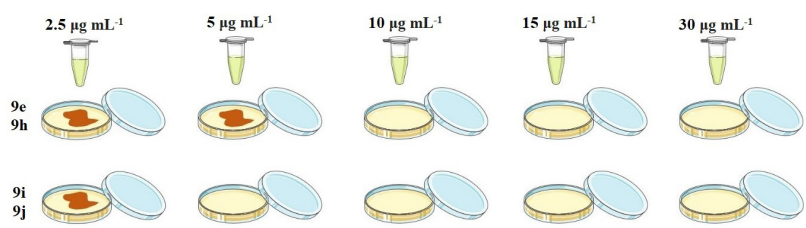

Figure 3. Scheme showing the result of the minimum inhibitory concentration. $9 \mathrm{e}$ and $9 \mathrm{~h}$ had concentrations found at $10 \mu \mathrm{g} \mathrm{mL}^{-1}$. 9i and $\mathbf{9 j}$ at $5 \mu \mathrm{g} \mathrm{mL}^{-1}$. Brown stain on the Petri dish represents bacterial growth.

Another interesting result is that when we used two different doses of compound $9 \mathbf{e}$, we observed that both had potent inhibitory effects at a concentration of $15 \mu \mathrm{g} \mathrm{mL}-1$ being able to inhibit bacterial multiplication with an inhibitory halo of $21 \mathrm{~mm}$ similar to streptomycin that was used as a control. However, the inhibitory effects at the concentration of 300 and $15 \mu \mathrm{g} \mathrm{mL}^{-1}$ when compared to streptomycin, showed a smaller effect at this concentration, demonstrating that compound $9 \mathrm{e}$ reached the inhibition plateau before the control drug.

When investigating the cytotoxicity of the formulated compounds, we observed that the compounds had low cytotoxicity. These results show that the initial concentration of $50 \mu \mathrm{g} \mathrm{mL} \mathrm{L}^{-1}$ for synthetic compounds, maintained cell viability above $80 \%$. At the highest concentration used
(1000 $\mu \mathrm{g} \mathrm{mL}^{-1}$ ), both $\mathbf{9 i}$ and $\mathbf{9 j}$ still maintained viability at around $60 \%$ (Figure 4).

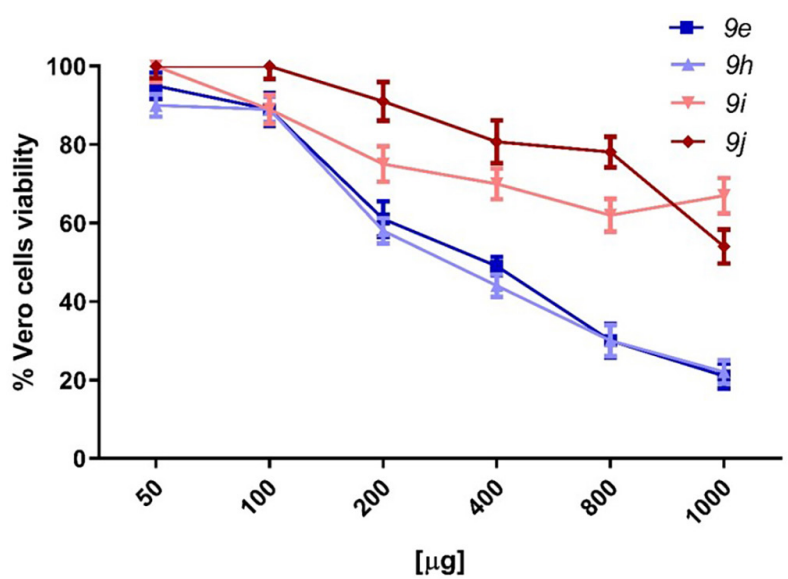

Figure 4. Graphical representation of the cytotoxicity assay from synthetic compounds.

Besides, the cytotoxicity results already established by our research group are complementary to the promising findings concerning the sensitivity test and MIC. This is because it is shown that synthetic compounds are not cytotoxic, maintaining good cell viability even in moderate to higher concentrations. This initial dose of $50 \mu \mathrm{g}$ suggests that the compounds can be used as an alternative treatment with a low risk of toxicity.

Comparisons of weight averages were performed in the three groups of $\mathrm{BALB} / \mathrm{c}$ mice to verify any alteration that could have occurred in any animal treated with the synthetic substance $9 \mathbf{i}$ (G1), in comparison with both control groups DMSO 1\% (G2) and saline (G3). The one-way ANOVA statistical test with Dunnett's post-test did not demonstrate any statistically significant difference between groups, even within each group during the experiment $(p>0.05)$ (Figure 5).

The weight assessment in mice, with any significant variations after the fourteen days of the experiment, was important since it suggests that the tested substances were not toxic to the animals. Also, it was noted that the mice's habits and behavior remained stable.

The mean values of urea, creatinine, TGP (ALT), and TGO (AST) (Figure 6), as well as their respective standard deviations, were analyzed (parametric one-way ANOVA test with Tukey's post-test for multiple comparisons) ( ${ }^{*} p<$ 0.05). Despite some significant differences found in the biochemical parameters of animals, these are close to normal values for mice found in the literature. ${ }^{44-46}$ Thus, substance 9i maintained the parameters of urea, creatinine and liver enzymes tested within the norm.

In the histological analysis of the animals, changes were observed in some mice organs from different groups, as shown in Table 1. 
Acute toxicity

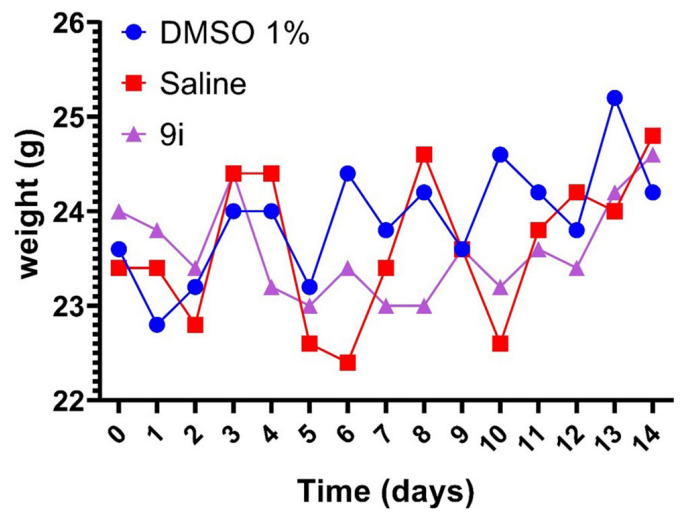

Figure 5. Acute toxicity. Mice weight evolution during 14-days experiment for DMSO $1 \%$, saline and $9 \mathbf{i} 175 \mathrm{mg} \mathrm{kg}^{-1}$. ${ }^{*} p<0.05$.

The group that received $9 \mathrm{i}$ had no changes in the brain, heart, duodenum and stomach. The $\mathbf{9 i}$ group presented liver with hepatic steatosis and the presence of necrotic hepatocytes around the central lobular veins (Figure 7a) in addition to the kidneys with mild hyaline degeneration (Figure 7b). However, the hepatic enzymes (TGO and TGP), urea and creatinine that indicate the renal function remained within the normal range. ${ }^{4-46}$ Some alterations were found in animals treated with $9 \mathbf{i}$. However, there were no deaths or behavioral changes despite the high concentration used for the acute toxicity test. In view of the high concentrations that are used in toxicity studies, above the therapeutic dose, some alterations in organs may occur. The alterations found in this study are compatible with alterations caused by other substances considered to have low toxicity. ${ }^{45,47}$ The DMSO group $1 \%$ presented necrotic areas in the pancreas (Figure 7c) and showed the kidneys with intense areas of hemorrhagic tubular necrosis (Figure 7d), also spleen with germinal (a)

Urea

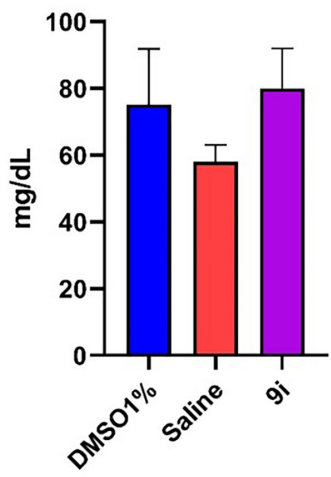

(e)

TGP

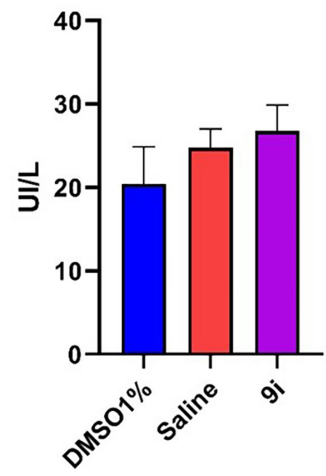

(b) Creatinine

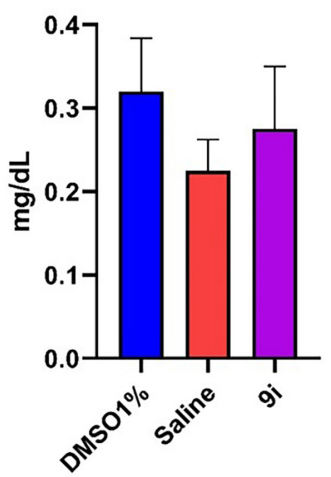

(d)

TGO

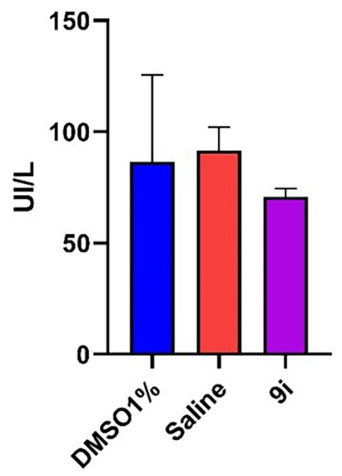

Figure 6. Biochemical analysis. (a) Mean value of urea. (b) Mean value of creatinine, DMSO 1\% ( $\left.{ }^{*} p=0.0120\right)$. (c) Mean value of TGP, DMSO $1 \%$ $\left({ }^{* *} p=0.0017\right)$ and saline $(* p=0.0473)$. (d) Mean value of TGO. All this means values are concerning from groups DMSO $1 \%$, saline and 9i. ${ }^{*} p<0.05$.

centers evident in the white pulp (Figure 7e), demonstrating some of the effects of the vehicle used, but these effects were also unable to cause deaths or change in weight and behavior.

Table 1. Demonstration of the results of the histological analysis of the organs of the BALB/c mice for each substance tested

\begin{tabular}{|c|c|c|c|}
\hline Organ & $9 \mathbf{i}$ & DMSO $1 \%$ & Saline \\
\hline Spleen & $\begin{array}{l}\text { spleens with centers germinative in } \\
\text { white pulp, except one animal (A5) }\end{array}$ & $\begin{array}{l}\text { three animals without amendment and } \\
\text { two with centers germinative in the } \\
\text { white pulp }\end{array}$ & $\begin{array}{l}\text { all the spleens presented centers } \\
\text { germinative in the pulp white, except } \\
\text { one animal (A5) }\end{array}$ \\
\hline Liver & $\begin{array}{c}\text { all with hepatic steatosis in livers, } \\
\text { except one animal (A2) }\end{array}$ & $\begin{array}{l}\text { all presented steatosis, } \\
\text { except one animal (A2) }\end{array}$ & $\begin{array}{l}\text { three animals presented steatosis, being } \\
\text { one discrete, and two animals not } \\
\text { owned change }\end{array}$ \\
\hline Kidney & $\begin{array}{c}\text { all without kidney changes, except } \\
\text { one animal, which presented discrete } \\
\text { hyaline degeneration }\end{array}$ & $\begin{array}{l}\text { all presented necrosis } \\
\text { areas tubular }\end{array}$ & $\begin{array}{l}\text { all without kidney changes, except two } \\
\text { animals, which presented hyperemia }\end{array}$ \\
\hline Brain & all without change & all without change & all without change \\
\hline Heart & all without change & all without change & $\begin{array}{l}\text { three animals unchanged and two } \\
\text { presented hyperemia }\end{array}$ \\
\hline Duodenum & all without change & $\begin{array}{l}\text { all without change except one (A2) that } \\
\text { presented necrosis areas }\end{array}$ & all without change \\
\hline Stomach & all without change & all without change & all without change \\
\hline
\end{tabular}

DMSO: dimethyl sulfoxide. 

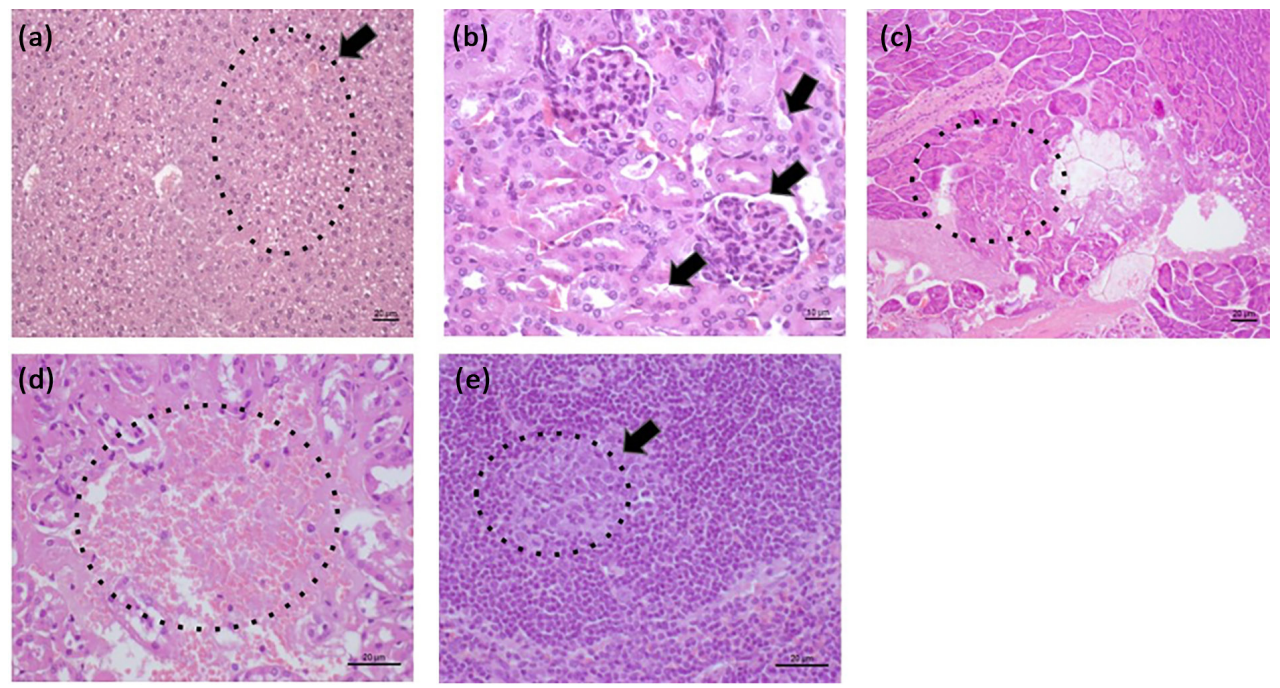

Figure 7. Changes in BALB/c mice toxicity tests on different organs (a) group 9i, liver- hepatic steatosis, area marked with an arrow within the dotted circle, 20x. (b) Group 9i, kidneys-mild hyaline degeneration, arrow, 40x. (c) DMSO group 1\%, pancreas-necrotic areas, dotted circle, 20x. (d) DMSO group 1\%, kidneys-intense areas of hemorrhagic tubular necrosis, dotted circle, 40x. (e) DMSO group 1\%, spleen-evidence of germinal centers in the white pulp, area within the dotted circle indicated by the arrow, 40x.

\section{Conclusions}

Based on the data obtained, we can conclude that compounds $9 \mathrm{e}, 9 \mathbf{h}, 9 \mathbf{i}$ and $9 \mathbf{j}$ presented low toxicity, even at moderate to high concentrations, showing themselves to be good candidates for use in controlling the multiplication of $S$. mutans acting in this way to reduce tooth decay. The compounds $9 \mathbf{e}, \mathbf{9 h}, \mathbf{9 i}$ and $\mathbf{9 j}$ are potent in inhibiting S. mutans compared with streptomycin, a drug of clinical use. Also, the $9 \mathbf{e}, 9 \mathbf{h}, 9 \mathbf{i}$ and $\mathbf{9 j}$ showed good inhibition of bacterial multiplication in the minimum inhibitory concentration test, being able to inhibit $S$. mutans even at low concentrations.

Thus, it is important to highlight that the compounds showed medium to high activity against $S$. mutans and are promising to become chemical agents for the treatment or prevention of caries. However, further studies are needed to prove the effectiveness of these compounds, such as in vivo tests.

\section{Supplementary Information}

Supplementary data are available free of charge at http://jbcs.sbq.org.br as PDF file.

\section{Acknowledgments}

This work was partially supported by FAPERJ grant numbers E-26/203.191/2017, E-26/010.101106/2018, E-26/202.800/2017, E-26/010.003002/2014, and E-26/203.246/2017; CNPq 301873/2019-4, 306011/20204, 308755/2018-9, and CAPES Financial Code 001. Also thank you to the Postgraduate Program in Sciences and Biotechnology of UFF (PPBI-UFF). We are grateful to Ilma
Ribeiro, veterinarian responsible for the bioterium of the Universidade Federal Fluminense, and Prof Renata Frauches Coimbra and her technical team in the Experimental Nutrition Laboratory (LABNE) of this university.

\section{Author Contributions}

Mônica P. Gomes was responsible for assays work; Eduardo M. Correia for biological assays work; Claudio C. C. dos Santos for biological assays work; Caroline S. Barros for biological assays work; Max Willian L. Gomes for biological assays work; Fernanda V. de Abreu for biological assays work; Leonardo S. Antunes for biological assays work; Vitor F. Ferreira for coordination of organic synthesis work, contributions to manuscript writing; Mariana C. Gonçalves for organic synthesis work; Gabriel O. de Resende for coordination of organic synthesis work, contributions to manuscript writing; Daniel T. G. Gonzaga for organic synthesis work; Carla E. C. Pinto for biological assays work; Izabel C. N. P. Paixão for coordination of biological assays work, contributions to manuscript writing; Fernando C. da Silva for coordination of organic synthesis work, contributions to manuscript writing.

\section{References}

1. Loesche, W. J.; Microbiol. Rev. 1986, 50, 353.

2. Marsh, P. D.; Int. J. Dent. Hyg. 2006, $4,3$.

3. Banas, J. A.; Front. Biosci. 2004, 9, 1267.

4. Hamada, S.; Koga, T.; Ooshima, T.; J. Dent. Res. 1984, 63, 407.

5. Petersen, F. C.; Assev, S.; van der Mei, H. C.; Busscher, H. J.; Scheie, A. A.; Infect. Immun. 2002, 70, 249.

6. Narvai, P. C.; Frazão, P.; Roncalli, A. G.; Antunes, J. L. F.; Rev. Panam. Salud Publica 2006, 19, 385. 
7. Marcenes, W.; Kassebaum, N. J.; Bernabé, E.; Flaxman, A.; Naghavi, M.; Lopez, A.; Murray, C. J. L.; J. Dent. Res. 2013, 92, 592 .

8. Singla, D.; Sharma, A.; Sachdev, V.; Chopra, R.; J. Clin. Diagn. Res. 2016, 10, ZC60.

9. Jones, M. E.; Draghi, D. C.; Thornsberry, C.; Karlowsky, J. A.; Sahm, D. F.; Wenzel, R. P.; Ann. Clin. Microbiol. Antimicrob. 2004, 3, 14 .

10. Rams, T. E.; Degener, J. E.; van Winkelhoff, A. J.; J. Periodontol. 2014, 85, 160.

11. Tacconelli, E.; Carrar, E.; Savoldi, A.; Harbarth, S.; Mendelson, M.; Monnet, D. L.; Pulcini, C.; Kahlmeter, G.; Kluytmans, J.; Carmeli, Y.; Ouellette, M.; Outterson, K.; Patel, J.; Cavaleri, M.; Cox, E. M.; Houchens, C. R.; Grayson, M. L.; Hansen, P.; Singh, N.; Theuretzbacher, U.; Magrini, N.; WHO Pathogens Priority List Working Group; Lancet Infect. Dis. 2018, 18, 318.

12. World Health Organization (WHO); Antimicrobial Resistance Global Report on Surveillance, WHO: Geneva, 2014, available at https://apps.who.int/iris/bitstream/ handle/10665/112642/9789241564748_eng.pdf, accessed in January 2022.

13. Ferreira, V. F.; de Carvalho, A. S.; Ferreira, P. G.; da Silva, F. C.; Med. Chem. 2021, 17, 1073.

14. Forezi, L. S. M.; Lima, C. G. S.; Amaral, A. A. P.; Ferreira, P. G.; de Souza, M. C. B. V.; Cunha, A. C.; da Silva, F. C.; Ferreira, V. F.; Chem. Rec. 2021, 21, 2782.

15. Ferreira, V. F.; Ferreira, P. G.; da Silva, T. B.; Portella, D. P.; da Silva, F. C.; Forezi, L. S. M.; Lima, C. G. S.; Souza, A. S.; Pauli, F. P.; Gonzaga, D. T. G. In Heterocycles: Synthesis, Reactions and Applications; Danielsen, J. M., ed.; Nova Science Publishers Inc.: New York, USA, 2020, ch. 1.

16. Moreira, C. S.; Silva, A. C. J. A.; Novais, J. S.; Figueiredo, A. M. S.; Ferreira, V. F.; da Rocha, D. R.; Castro, H. C.; J. Appl. Microbiol. 2016, 122, 651.

17. Novais, J. S.; Moreira, C. S.; Silva, A. C. J. A.; Loureiro, R. S.; Figueiredo, A. M. S.; Ferreira, V. F.; Castro, H. C.; da Rocha, D. R.; Microb. Pathog. 2018, 118, 105.

18. Boothman, D. A.; Trask, D. K.; Pardee, A. B.; Cancer Res. 1989, 49, 605.

19. Jantová, S.; Greif, G.; Pavlovicová, R.; Cipák, L.; Folia Microbiol. 1998, 43, 75.

20. Wang, X. L.; Wan, K.; Zhou, C. H.; Eur. J. Med. Chem. 2010, 45,4631 .

21. Sturgess, M. A.; Yang, K.; US pat. $20030232801 A 1,2003$.

22. GraphPad Prism, version 8.00; GraphPad Software, Inc., USA, 2020.

23. Tricarico, P. M.; Caracciolo, I.; Crovella, S.; D’Agaro, P.; Biochem. Biophys. Res. Comm. 2017, 492, 597.

24. OECD Guideline for Testing of Chemicals, https://www.oecd. org/chemicalsafety/risk-assessment/1948378.pdf, accessed in January 2022.
25. Epi Info, 6.04; Division of Health Informatics \& Surveillance (DHIS), Center for Surveillance, Epidemiology \& Laboratory Services (CSELS), Washington, D.C., USA, 2001.

26. GraphPad InStat, version 3; GraphPad Software, Inc., USA, 2001.

27. Kassebaum, N. J.; Bernabé, E.; Dahiya, M.; Bhandari, B.; Murray, C. J. L.; Marcenes, W.; J. Dent. Res. 2015, 94, 650.

28. Fejerskov, O.; Community Dent. Oral Epidemiol. 1997, $25,5$.

29. Saunders, R. H.; Meyerowitz, C.; Dent. Clin. North Am. 2005, 49, 293.

30. Davidson, J. R.; Blevins, W. T.; Feary, T. W.; Antimicrob. Agents Chemother. 1976, 9, 145.

31. Poulsen, G. B.; Plant Breed. 1996, 115, 209.

32. Watanakunakorn, C.; Glotzbecker, C.; J. Med. Microbiol. 1977, 10, 133.

33. Baker, C. N.; Thornsberry, C.; Antimicrob. Agents Chemother. 1974, 5, 268.

34. Beg, A. M.; Jones, M. N.; Miller-Torbert, T.; Holt, R. G.; Biochem. Biophys. Res. Commun. 2002, 298, 75.

35. Little, W. A.; Thomson, L. A.; Bowen, W. H.; Antimicrob. Agents Chemother. 1979, 15, 440.

36. Nagata, E.; Okayama, H.; Ito, H.-O.; Yamashita, Y.; Inoue, M.; Oho, T.; Oral Microbiol. Immunol. 2006, 21, 420.

37. Russell, M. W.; Wu, H.; Crit. Rev. Oral Biol. Med. 1990, 1, 191.

38. Yamamoto, Y.; Igarashi, T.; J. Dent. Res. 2004, 2, 534.

39. Zhou, C. H.; Wang, Y.; Curr. Med. Chem. 2012, 19, 239.

40. Gao, F.; Wang, T.; Xiao, J.; Huang, G.; Eur. J. Med. Chem. 2019, 173, 274.

41. Holla, B. S.; Mahalinga, M.; Karthikeyan, M. S.; Poojary, B.; Akberali, P. M.; Kumari, N. S.; Eur. J. Med. Chem. 2005, 40, 1173.

42. Hoffman, H. L.; Ernst, E. J.; Klepser, M. E.; Expert Opin. Invest. Drugs 2000, 9, 593.

43. Munro, A. W.; Lindsay, J. G.; Mol. Microbiol. 1996, $20,1115$.

44. Barros, C. S.; Gomes, M. W. L.; Gomes, R. S. P.; Melchiades, V.; Nogueira, C. C. R.; Cirne-Santos, C. C.; Garrido, V.; Pinto, C. E. C.; Teixeira, V. L.; Paixão, I. C. N. P.; J. Med. Plants Res. 2018, 12, 217.

45. Garrido, V.; Barros, C. S.; Tonelli, M.; Teixeira, G.; Ocampo, P.; Bezerra, G.; Giongo, V.; Paixão, I. P.; Int. J. Pharm. Res. 2016, 6, 217.

46. Badary, O. A.; Al-Shabanah, O. A.; Nagi, M. N.; Al-Bekairi, A. M.; Elmazar, M. M. A.; Drug Dev. Res. 1998, 44, 56.

47. Garrido, V.; Barros, C.; Melchiades, V. A.; Fonseca, R. R.; Pinheiro, S.; Ocampo, P.; Teixeira, V. L.; Cavalcanti, D. N.; Giongo, V.; Ratcliffe, N. A.; Teixeira, G.; Paixão, I. C. N. P.; Regul. Toxicol. Pharmacol. 2017, 86, 193.

Submitted: November 17, 2021

Published online: January 14, 2022 